\title{
of the Th1 response to mycobacteria
}

3 Nayan D Bhattacharyya ${ }^{1,2}$, Claudio Counoupas ${ }^{3,2}$, Lina Daniel ${ }^{1,2}$, Guoliang Zhang ${ }^{4,1,2}$, Stuart J

4 Cook $^{5}$, Taylor A Cootes ${ }^{1,2}$, Sebastian A Stifter ${ }^{1,2}$, David G Bowen ${ }^{7,8}$, James A Triccas ${ }^{3,2,6}$, Patrick

5 Bertolino $^{7,8}$, Warwick J Britton ${ }^{2}$ \& Carl G Feng ${ }^{1,2,6^{*}}$

\section{Affiliations:}

$8{ }^{1}$ Immunology and Host Defense Group, Department of Infectious Diseases and Immunology,

9 School of Medical Sciences, Faculty of Medicine \& Health, The University of Sydney, NSW,

$10 \quad 2006$, Australia.

$11{ }^{2}$ Tuberculosis Research Program, Centenary Institute, Royal Prince Alfred Hospital,

12 Camperdown, NSW, 2050, Australia.

$13{ }^{3}$ Microbial Pathogenesis and Immunity Group, Department of Infectious Diseases and

14 Immunology, School of Medical Sciences, Faculty of Medicine \& Health, University of Sydney,

15 NSW, 2006, Australia.

$16{ }^{4}$ National Clinical Research Center for Infectious Diseases, Guangdong Key Laboratory of

17 Emerging Infectious Diseases, Shenzhen Third People's Hospital, Southern

18 University of Science and Technology, Shenzhen, China.

195 Immune Imaging Program, Centenary Institute, Royal Prince Alfred Hospital, Camperdown,

20 NSW, 2050, Australia.

$21{ }^{6}$ Marie Bashir Institute for Infectious Diseases and Biosecurity, The University of Sydney,

22 Sydney, NSW, 2006, Australia.

$23{ }^{7}$ Liver Immunology Program, Centenary Institute, Royal Prince Alfred Hospital, Camperdown, 24 NSW, 2050, Australia.

$25{ }^{8}$ AW Morrow Gastroenterology and Liver Centre, Royal Prince Alfred Hospital, Camperdown, 26 NSW, 2050, Australia. 


\section{Abstract:}

31 The quality of T cell responses depends on the lymphocytes' ability to undergo clonal expansion, 32 acquire effector functions and traffic to the site of infection. Although TCR signal strength is 33 thought to dominantly shape the $\mathrm{T}$ cell response, by using TCR transgenic $\mathrm{CD} 4^{+} \mathrm{T}$ cells with 34 different pMHC binding affinity, we reveal that TCR affinity does not control Th1 effector 35 function acquisition nor the functional output of individual effectors following mycobacterial 36 infection. Rather, TCR affinity calibrates the rate of cell division to synchronize the distinct 37 processes of $\mathrm{T}$ cell proliferation, differentiation and trafficking. By timing cell division-dependent IL-12R expression, TCR affinity controls when T cells become receptive to Th1-imprinting IL-12

39 signals, determining the emergence and magnitude of the Th1 effector pool. These findings reveal

40 a distinct yet cooperative role for IL-12 and TCR signalling in Th1 differentiation and suggests

41 that the temporal activation of clones with different TCR affinity is a major strategy to coordinate 42 immune surveillance against persistent pathogens.

\section{Keywords:}

45 TCR affinity, TCR signal, Th1 response, cell division, IL-12, mycobacteria. 
Introduction:

The successful containment of invading pathogens requires the rapid generation of large numbers of antigen-specific T cells with the correct effector function. This involves the activation of distinct programs, including $\mathrm{T}$ cell proliferation, differentiation, and migration. Failure in activating or regulating these programs results in impaired host defense. The majority of studies have focused on one or a limited number of $\mathrm{CD}^{+} \mathrm{T}$ cell programs, such as, the magnitude of population expansion or expression of master regulators of transcription. There is little information available as to whether these processes, which operate at different biological scales spanning from the molecule to the tissue, are individually or cooperatively regulated in vivo. Indeed, in vitro studies have already suggested a link between cell division and differentiation, demonstrating that cell division progression is associated with increased expression of signature Th cytokines (1-3).

The pool of naive T cells in vivo is diverse and contains clones that express distinct TCRs recognizing different peptide:MHC (pMHC) complexes. It is estimated that there are anywhere between twenty and one thousand naive T cells that possess the same pMHC specificity $(4,5)$, each with different binding affinities. The strength of TCR signals, regulated by the TCRs affinity, the density of pMHC and co-stimulatory molecules on antigen presenting cells (APCs), regulates downstream $\mathrm{T}$ cell activation and function $(6,7)$. While high affinity TCR signals in cytotoxic $\mathrm{CD}^{+} \mathrm{T}$ lymphocytes accelerate cell division and prolong population expansion $(8,9)$, it delays their migration from secondary lymphoid organs (SLOs) $(9,10)$ resulting in impaired pathogen control (10). Similarly, strong TCR signals enhance the expansion of CD4 ${ }^{+} \mathrm{T}$ cell populations (1113).

Defining the role of TCR signaling strength in the $\mathrm{CD}^{+}$lymphocyte response is challenging because of the functional heterogeneity in helper $\mathrm{T}$ cell populations. The effector 
function of Th populations is instructed by signals from the TCR as well as from pathogenconditioned accessory cells and APCs. Historically, investigations into Th cell differentiation have focused on "qualitative" T cell-extrinsic cytokine signals $(7,14)$. In the case of Th1 differentiation, the innate cytokine IL-12 promotes the generation of interferon- $\gamma(\mathrm{IFN}-\gamma)$-producing effectors $(15$, 16) and host survival following infection with intracellular pathogens (17). Recent studies have suggested a role for "quantitative" differences in TCR signal strength in regulating CD4 $4^{+} \mathrm{T}$ cell differentiation $(12,18-20)$. Potent TCR signaling is associated with the generation of Th1 $(18,19)$ or Tfh cells $(11,20,21)$. Mechanisms proposed to mediate strong TCR signal-driven Th lineage commitment vary depending on experimental settings. For example, IL-2 $(12,13,19)$ and IL-12 receptor signaling (18) have each been suggested to contribute to the generation of Th1 populations following potent TCR stimulation. The model-dependent function of strong TCR signaling suggests a potential interplay between quantitative TCR and qualitative environmental signals in instructing Th differentiation. Currently, the relative role of TCR and innate cytokine signals in lineage commitment and the mechanisms integrating these signals is unknown.

In this study, we developed a $\mathrm{T}$ cell adoptive transfer model using $\mathrm{CD}^{+} \mathrm{T}$ cells from two TCR transgenic (Tg) mouse lines that recognize the same epitope of the Mycobacterium tuberculosis protein Early Secretory Antigenic Target 6 (ESAT-6, E6), with different binding affinities. Following T cell transfer, WT or IL-12-deficient recipient mice were infected with a recombinant Mycobacterium bovis Bacillus Calmette-Guérin-expressing E6 (BCG-E6). By tracking transgenic $\mathrm{CD}^{+} \mathrm{T}$ cells across multiple time-points and in different tissues following intravenous (i.v.) BCG infection, we reveal that by adjusting the rate of cell division, a major function of TCR affinity is to determine the speed and magnitude of the $\mathrm{CD}^{+} \mathrm{T}$ cell response. Moreover, TCR affinity plays a minimal role in specifying $\mathrm{T}$ helper cell effector function. 
93 However, by regulating cell division-dependent IL-12R $\beta 2$ expression, TCR affinity controls when

94 T cells become receptive to IL-12 and acquire Th1 effector function. Since high affinity CD4 ${ }^{+} \mathrm{T}$

95 cells also migrate to infected non-lymphoid tissues faster than their low affinity counterparts, our

96 findings show that TCR affinity coordinates multiple programs to determine the overall potency

97 of the Th cell response to infection. They also suggest that the temporal activation of distinct $\mathrm{T}$

98 cell clones is a mechanism controlling the initiation and maintenance of Th1 immunity against

99 persistent infection.

100 


\section{Results:}

\section{CD4 $^{+}$T cells with high affinity TCRs are primed earlier and expand further than low affinity} cells during mycobacterial infection

To allow a direct comparison of the current and previous studies, which were focused primarily on $\mathrm{T}$ cell responses in the spleen following i.v. infection, we developed an i.v. BCG infection and $\mathrm{CD}^{+} \mathrm{T}$ cell transfer model (Fig. 1A). BCG delivered by the i.v. route infects primarily the liver and spleen, with the liver being the main site of infection (Fig. S1A). To study the contribution of intrinsic variations in TCR signal strength to the $\mathrm{CD}^{+} \mathrm{T}$ cell response, recipient mice were adoptively transferred with GFP-expressing $\mathrm{CD}^{+} \mathrm{T}$ cells isolated from two strains of $\mathrm{TCR} \mathrm{Tg}$ mice (C7 and C24). The TCR of C7 and C24 cells recognize the ESAT61-20 (E6) epitope with low/intermediate and high binding affinity, respectively (22). Recipient mice were then infected with a recombinant $\mathrm{BCG}$ that expresses the E6 epitope (BCG-E6) recognized by the T cells. The donor E6-specific $\mathrm{CD}^{+} \mathrm{T}$ cells were distinguished from endogenous $\mathrm{T}$ lymphocytes by their expression of GFP (Fig. 1B).

In this model, both C7 (low affinity) and C24 (high affinity) T cells were detected in the spleen, liver and liver draining lymph nodes (dLN) as early as day 1 after i.v. BCG infection (Fig. 1C). Cell division, assessed by CTV dye dilution, was first detected in Tg cells in the spleen, indicating that the organ is the primary site of $\mathrm{T}$ cell priming in this model. $\mathrm{CD} 4^{+} \mathrm{T}$ cell expansion peaked at day 3 post-infection (p.i.) in the spleen compared to day 6 p.i. in the liver and its draining LN (Fig. 1D). Importantly, high affinity C24 cell populations expanded more than lower affinity C7 cells in the spleen, $\mathrm{dLN}$, and liver. Although high affinity C24 T cells demonstrated lower TCR expression when compared to lower affinity C7 cells at day 6 p.i. in the spleen (Fig. S1B), the former Tg T cells exhibited unimpaired IFN- $\gamma$ expression when re-stimulated with E6 peptide or 
A

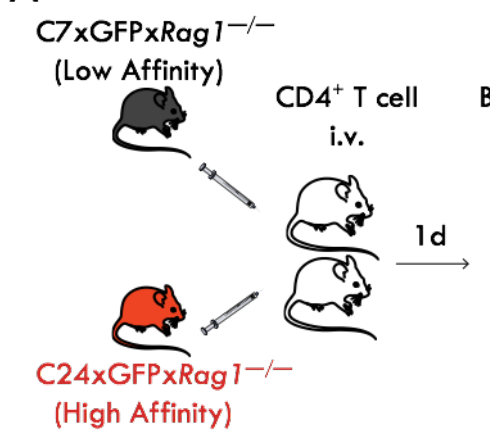

BCG-ESAT6

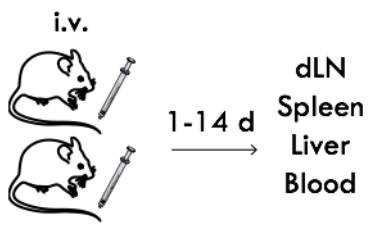

(High Affinity)
B

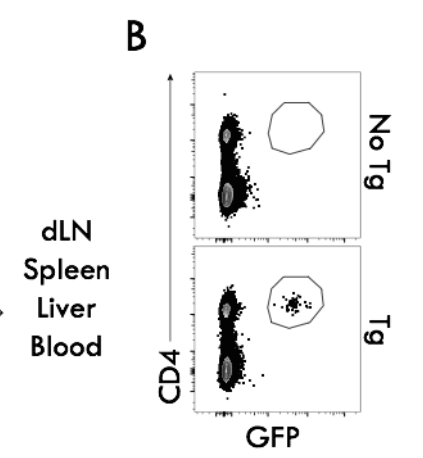

D

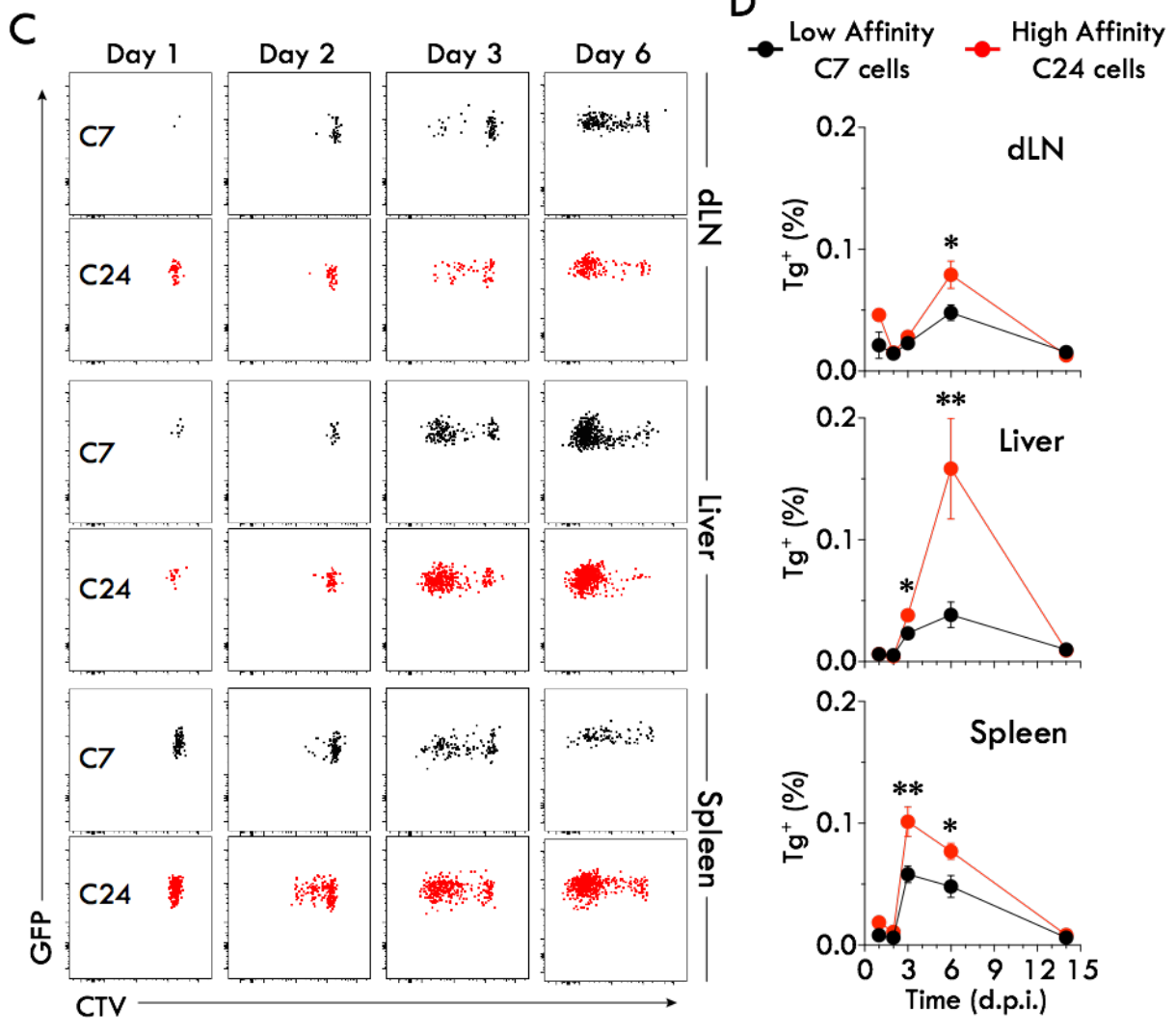

Figure. 1. $\mathrm{CD4}^{+} \mathrm{T}$ cells with high affinity $\mathrm{TCRs}$ undergo enhanced accumulation in lymphoid

\section{and non-lymphoid organs following mycobacterial infection.}

(A) Schematic diagram illustrating the adoptive transfer and infection model. Magnetically-purified $\mathrm{CD}^{+} \mathrm{T}$ cells from C7xGFPxRag1 $1^{-1}$ or C24xGFPxRag1 ${ }^{-1}$ TCR transgenic (Tg) mice were transferred i.v. into separate intact, naïve C57BL/6 (B6) recipients $\left(10^{5} /\right.$ mouse) $1 \mathrm{~d}$ prior to i.v. inoculation with BCG-E6 $\left(10^{6} \mathrm{CFU}\right.$ / mouse). The liver-draining lymph node (dLN), spleen, liver and spleen was collected at various time-points p.i.. (B) Flow cytometric detection of GFP-expressing TCR Tg T cells in the spleens of recipient mice that did not receive or received transgenic T cells 3 days after BCG-E6 infection. (C) Flow cytometric analysis of CTV dilution in GFP-expressing $\mathrm{CD} 4{ }^{+} \mathrm{C} 7$ and $\mathrm{C} 24$ cells in the $\mathrm{dLN}$, liver and spleen at day 1, 2, 3 and 6 p.i.. Black and red FACS plots represent $\mathrm{C} 7$ and $\mathrm{C} 24 \mathrm{CD}^{+} \mathrm{T}$ cells, respectively. (D) Frequency of $\mathrm{GFP}^{+} \mathrm{C} 7$ or $\mathrm{C} 24$ cells in the dLN, liver and spleen at the indicated time-points. Data are pooled from three independent experiments with similar trends; Data shown are the mean percentage \pm sem ( $\mathrm{n}>8$ mice / group / time point). Symbols or lines in black and red represent C7 and C24 cells, respectively. Statistical differences between C7 and C24 cells were determined by Student's t-test $\left({ }^{*} \mathrm{p}<0.05, * * \mathrm{p}<0.01\right)$. 

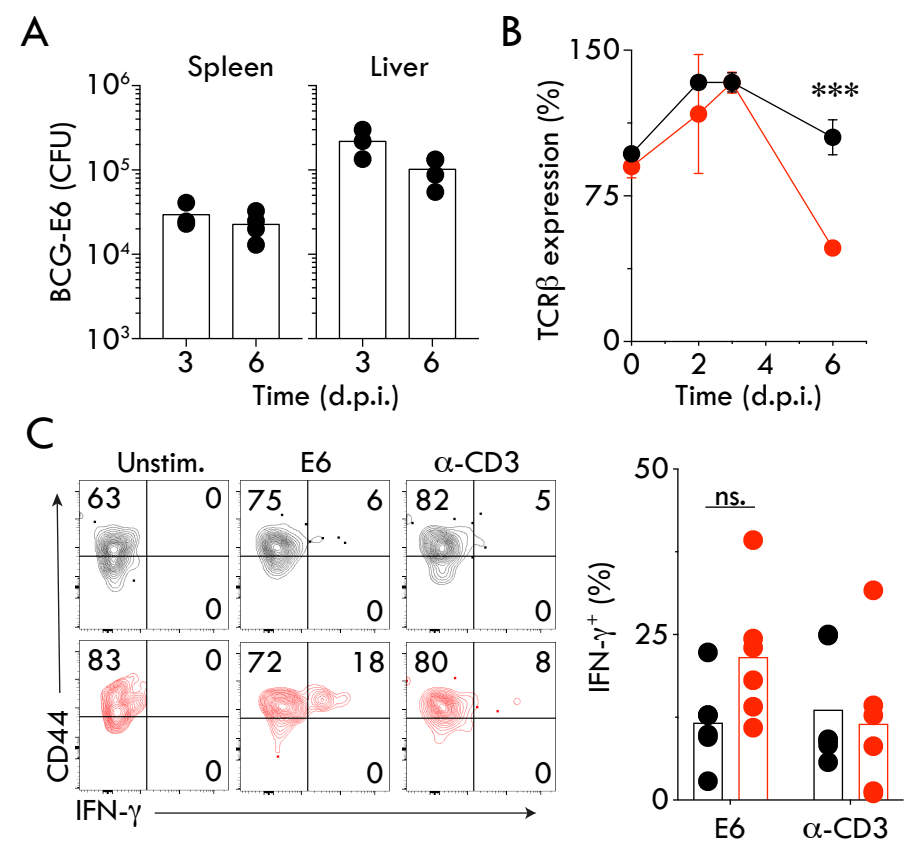

\section{Figure. S1. TCR downregulation in high affinity C24 cells does not affect antigen reactivity ex vivo and the distribution of BCG-E6 following i.v infection.}

(A) Bacterial loads in the spleen and liver of B6 mice (without the transfer of TCR Tg CD4 ${ }^{+} \mathrm{T}$ cells) assessed at day 3 and 6 after i.v. BCG-E6 inoculation ( $\mathrm{n}=4$ mice / time-point). (B-C) C7 and C24 CD4 ${ }^{+}$cells were transferred i.v. into naive B6 recipients 1 day prior to i.v. inoculation with BCG-E6. (B) Flow cytometric analysis of TCR $\beta$ expression on $\mathrm{C} 7$ and $\mathrm{C} 24$ cells in the spleens of mice at the indicated time-points. TCR $\beta$ expression on TCR Tg cells is represented as a percentage relative to the MFI of TCR $\beta$ on endogenous $\mathrm{CD}^{-} 4^{-} \mathrm{CD}^{+} \mathrm{T}$ cells. Data are representative of three independent experiments. Symbols denote group means and bars show sem ( $\mathrm{n}=3$ mice / group). (C) CD44 and IFN- $\gamma$ expression in C7 and C24 cells from the spleens of mice 6 days after i.v. inoculation with BCG-E6. Splenocytes were left unstimulated or re-stimulated for $5 \mathrm{~h}$ with either the E6 peptide $(1 \mu \mathrm{g} / \mathrm{mL})$ or soluble agonistic anti-CD3 $\mathrm{mAb}(1 \mu \mathrm{g} / \mathrm{mL})$ in the presence of BFA. Representative FACS plots and summary graphs of pooled data from two experiments are shown ( $n=6$ mice / group). Symbols denote individual mice and the open bars represent group means. Black and red flow cytometry plots or symbols represent C7 and C24 cells, respectively. Statistical differences between C7 and C24 cells were determined using the Student's t test $\left(\mathrm{p}^{* * *}<0.001\right)$. 
polyclonal anti-CD3 ex vivo (Fig. S1C). These data indicate that TCR downregulation on C24 cells minimally affects their ability to recognize cognate antigens.

\section{High affinity $\mathrm{CD4}^{+} \mathrm{T}$ cells undergo accelerated activation, proliferation and differentiation}

To investigate whether the accelerated and greater expansion of high affinity $\mathrm{C} 24$ cells resulted from their enhanced activation and cell division, we first examined the kinetics of $\mathrm{T}$ cell activation and proliferation in vivo after adoptive T cell transfer and BCG-E6 infection. A greater fraction of C24 cells upregulated the activation markers CD44 and CD25 than lower affinity clones at day 2 in the spleen (Fig. 2A). By day 3, however, high and low affinity $\mathrm{T}$ cells expressed similar levels of CD44. Elevated $\mathrm{CD} 25$ expression on $\mathrm{CD}^{+} \mathrm{T}$ cells was transient, with $\mathrm{CD} 25$ expression returning to negligible levels by day 6 p.i., irrespective of TCR affinity.

Consistent with their increased activation, the majority of high affinity C24 cells had undergone at least one additional division when compared to their lower affinity counterparts at day 3 p.i. in vivo (Fig. 2B). The enhanced cell cycling of high affinity $\mathrm{T}$ cells was further demonstrated by an increased percentage of $\mathrm{Ki}-67^{+} \mathrm{C} 24$ cells in the spleen (Fig. 2C). Mathematical modelling based on the fraction of divided cells over time $(8,23,24)$ (Fig. S2A) estimated that high affinity C24 cells entered cell division $6 \mathrm{~h}$ earlier than their lower affinity $\mathrm{C} 7$ counterparts in vivo (Fig. $2 \mathrm{D}, 65 \mathrm{~h}$ vs. $71 \mathrm{~h}$ ). One of the hallmarks of the immune response to mycobacterial infection is the generation of Th1 cells. When compared to lower affinity C7 cells, a greater proportion of high affinity $\mathrm{C} 24$ cells upregulated T-bet and the Th1-associated chemokine receptor CXCR3 at day 2 p.i. (Fig. 2E). However, these differences were eventually diminished at later time points in the spleen (Fig. 2F). Together with the activation kinetics, these findings reveal that the impact of TCR signal strength on Th1 activation and differentiation is time dependent. 

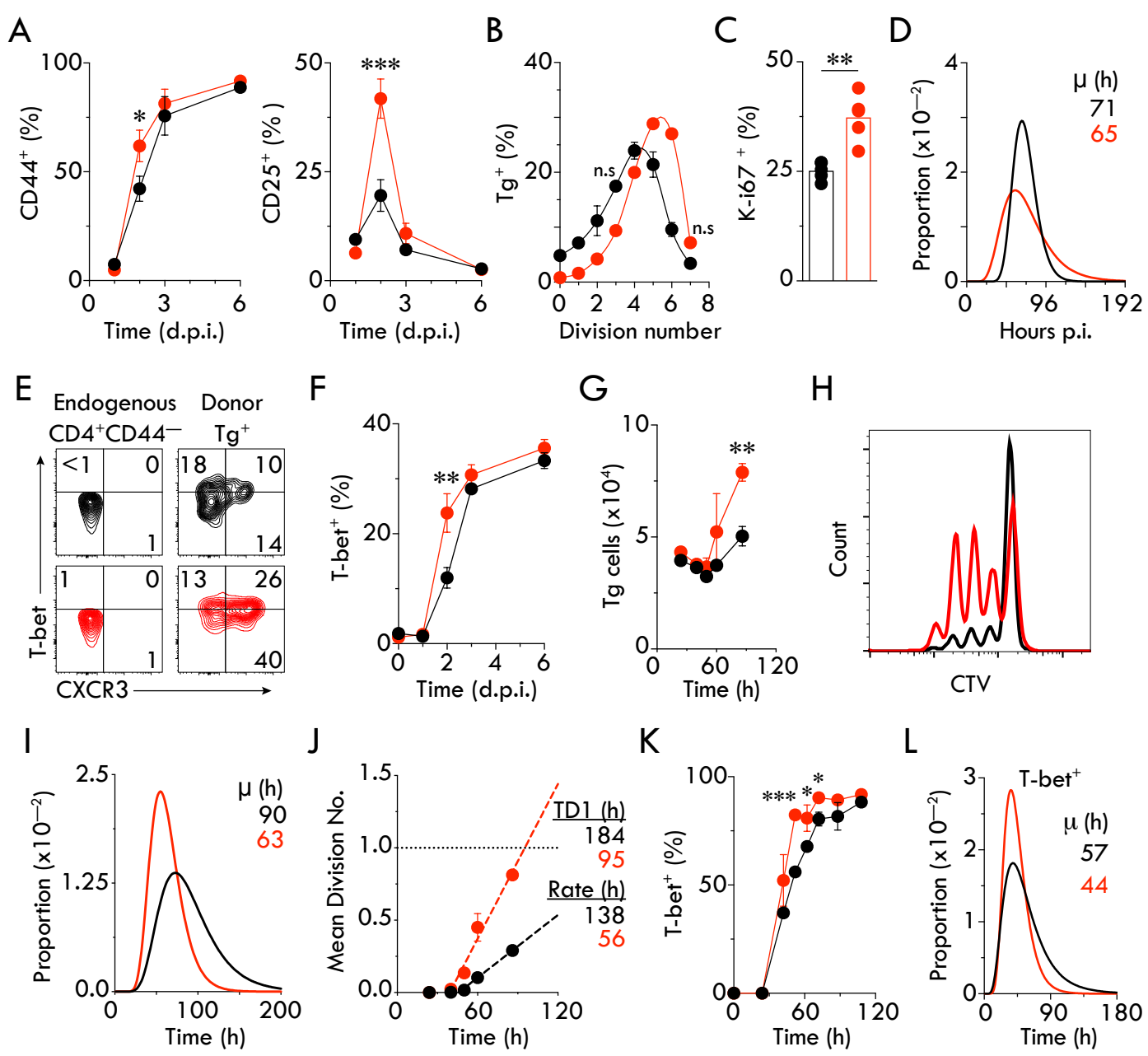

Figure. 2. Strong TCR signaling accelerates the activation, proliferation and differentiation

\section{of Th1 cells.}

(A-F) CTV-labelled C7 and C24 cells were transferred into naive B6 recipients 1 day prior to inoculation with BCG-E6. The activation and proliferation of TCR Tg cells in the spleen was determined using flow cytometry. (A) Flow cytometric analysis of CD44 and CD25 expression on C7 and C24 cells at the indicated time-points. Data are pooled from at least three independent experiments with similar trends. Data shown are the mean percentage $\pm \operatorname{sem}$ ( $\mathrm{n}>10$ mice / group / time point). (B) Frequency of Tg cells in each division 3 d.p.i. determined by flow cytometry. Data are representative of four independent experiments with similar results. Symbols and bars denote the group mean $\pm \operatorname{sem}(\mathrm{n}=3$ mice / group), respectively. The difference in the proportion of C7 and $\mathrm{C} 24$ cells in each division was statistically significant (at least $\mathrm{p}<0.05$ ) for all division numbers, unless indicated otherwise. (C) Percentage of Ki-67-expressing Tg cells in the spleen 3 days after BCG-E6 inoculation determined by flow cytometry. Closed circles represent individual mice and bars denote the group mean. Data are representative of two independent experiments with similar results $(\mathrm{n}=4$ mice / group). (D) Time to first division determined by CTV dilution in vivo. Best-fit log normal probability distribution describing the mean time to first division (C7: $\mu=71.1 \mathrm{~h}$, sd. $=0.2 \mathrm{~h} ; \mathrm{C} 24: \mu=65.2 \mathrm{~h}$, sd. $=0.2 \mathrm{~h}$ ). Data are representative of two independent experiments ( $\mathrm{n}=5$ mice / group). (E) Flow cytometric analysis of T-bet and CXCR3 expression in donor TCR Tg cells $\left(\mathrm{GFP}^{+} \mathrm{CD} 4^{+}\right)$at 2 d.p.i.. Endogenous naïve $\mathrm{CD}^{+}$cells $\left(\mathrm{GFP}^{-} \mathrm{CD}^{+} \mathrm{CD}^{-} 4^{-}\right)$within the same recipient spleen were used as controls. (F) Percentage of T-bet expression at indicated time points p.i.. Data are pooled from three independent experiments Symbols and bars denote the group mean \pm sem (3-10 mice / group). (G-L) Purified C7 and C24 Tg cells were CTV-labelled and cultured with CD4-depleted splenocytes isolated 
from naïve B6 mice in the presence of IL-12 $(5 \mathrm{ng} / \mathrm{mL})$, anti-IL-4 $(10 \mu \mathrm{g} / \mathrm{mL})$, anti-IFN- $\gamma(10 \mu \mathrm{g} / \mathrm{mL})$ and the E6 peptide $(0.05 \mu \mathrm{g} / \mathrm{mL})$. (G) Accumulation of C7 and C24 Tg cells in vitro. Data shown are the mean numbers \pm sd of triplicate cultures and representative of three independent experiments. (H) Representative flow cytometry plot of CTV dilution in C7 and C24 Tg cells at $60 \mathrm{~h}$. (I) Time to first division determined by CTV dilution in vitro. Best-fit log normal probability distribution describing the mean time to first division (C7: $\mu=$ $89.73 \mathrm{~h}$, sd. $=1.62 \mathrm{~h} ; \mathrm{C} 24: \mu=62.89 \mathrm{~h}$, sd. $=1.55 \mathrm{~h})$. (J) The mean division number (MDN) of precursor $\mathrm{C} 7$ and $\mathrm{C} 24$ cells at each time point was fitted with a linear regression $(\mathrm{C} 7: \mathrm{y}=0.007224 \mathrm{x}-0.3307 ; \mathrm{C} 24: \mathrm{y}=$ $0.01784 \mathrm{x}-0.6994)$. The time to first division is calculated by solving for $\mathrm{x}$ (time), when the MDN $=1(\mathrm{C} 7=$ $184.21 \mathrm{~h}, \mathrm{C} 24=95.26 \mathrm{~h})$. The reciprocal of the slope provides an estimate of the rate of cell division $(\mathrm{C} 7=$ $138.43 \mathrm{~h}, \mathrm{C} 24=56.05 \mathrm{~h}$ ). (K) Kinetic analysis of T-bet expression in C7 and C24 T cells by flow cytometry. Data shown are the mean percentage of $\mathrm{T}-\mathrm{bet}^{+} \mathrm{Tg}$ cells \pm sd of triplicate cultures and representative of three independent experiments. (L) Quantification of T-bet induction time in Tg cells in vitro. Best-fit log normal probability distribution describing the mean time to T-bet expression $(\mathrm{C} 7: \mu=56.5 \mathrm{~h}$, sd. $=1.4 \mathrm{~h} ; \mathrm{C} 24: \mu=44.2$ $\mathrm{h}$, sd. $=1.6 \mathrm{~h}$ ). Lines and symbols that are black or red represent C7 and C24 cells, respectively. Statistical differences between C7 and C24 cells were determined by Student t-test analysis $\left({ }^{*} \mathrm{p}<0.05,{ }^{* *} \mathrm{p}<0.01,{ }^{* * *} \mathrm{p}<\right.$ 0.001 , ns., not statistically significant). 

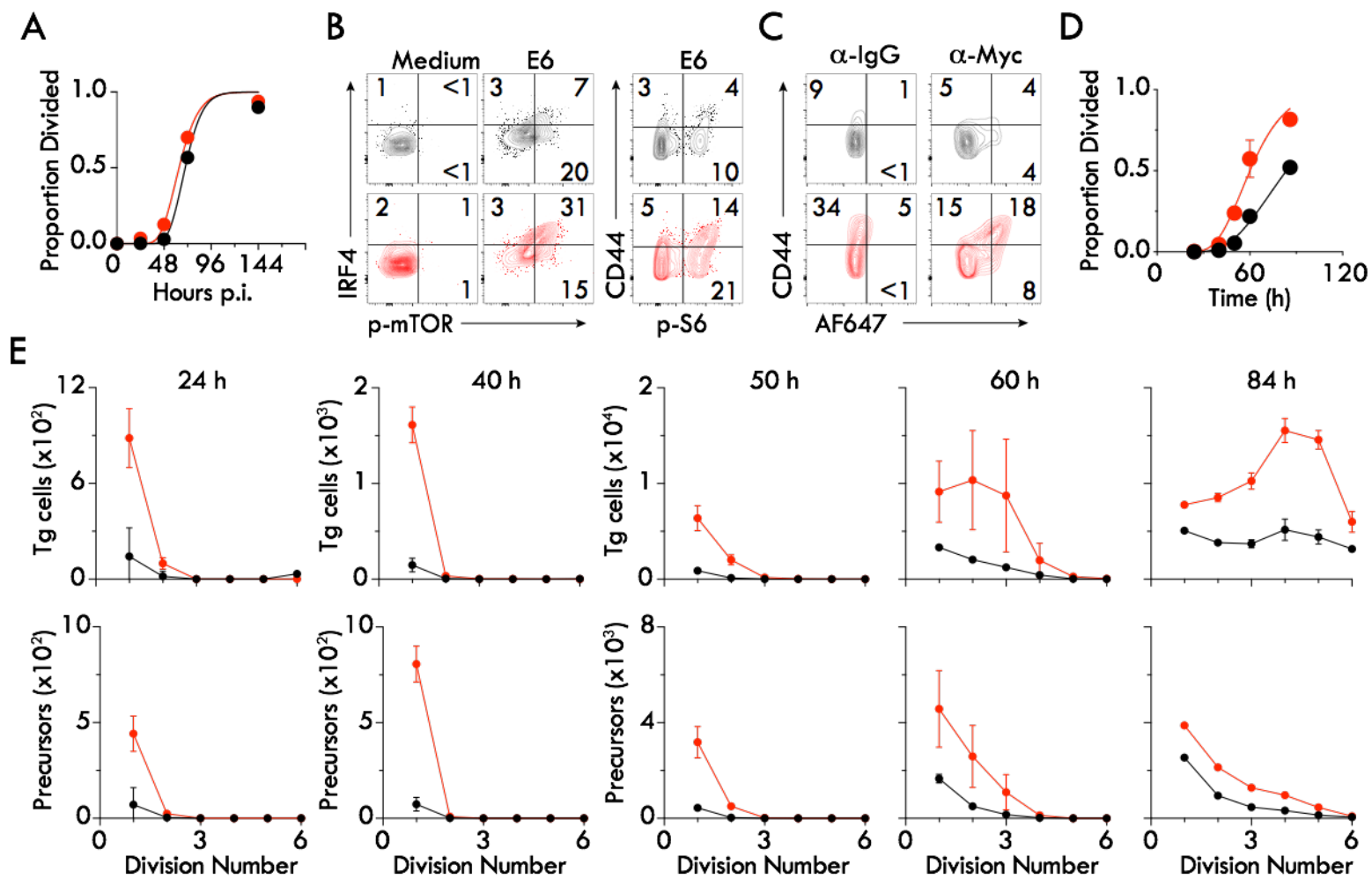

\section{Figure. S2. T cell activation and modelling of cell division kinetics.}

(A) $\mathrm{C} 7$ and $\mathrm{C} 24 \mathrm{CD}^{+}$cells were transferred i.v. into naive $\mathrm{B} 6$ recipients 1 day prior to i.v. inoculation with BCG-E6. At each time-point, the average proportion of undivided C7 and C24 cells in the dLN, liver and spleen were determined using flow cytometry, and fitted with an inverted cumulative lognormal distribution (C7: $\mu=$ 4.243 , sd. $=0.1989 ; \mathrm{C} 24: \mu=4.148$, sd. $=0.2441)$ and used to estimate the best fit log normal distribution describing the time to first division (Fig. 2D). Lines and symbols that are black or red represent C7 and C24 cells, respectively. Data shown are representative of two independent experiments with similar results. Symbols denote the group mean ( $\mathrm{n}=3-4$ mice / group). (B-E) CTV-labelled C7 and C24 CD4 ${ }^{+} \mathrm{T}$ cells were cultured with CD4-depleted splenocytes in the presence of IL-12, and anti-IL-4 and anti-IFN- $\gamma$ mAbs, with or without E6 peptide. (B) Flow cytometric analysis of IRF4 and phosphorylated mTOR (p-mTOR), CD44 and phosphorylated ribosomal S6 (p-S6) at $24 \mathrm{~h}$. (C) Expression of CD44 and Myc $24 \mathrm{~h}$ after peptide activation was assessed by incubating $\mathrm{C} 7$ and $\mathrm{C} 24$ cells with either anti-Myc or rabbit IgG istotype control primary antibodies prior to staining with anti-rabbit IgG conjugated to AF647. Flow cytometry plots that are black or red represent C7 and C24 cells, respectively. Data shown are representative of two independent experiments with similar results. (D) The proportion of undivided C7 and C24 cells at each time point was calculated and was fitted with an inverted cumulative lognormal distribution $(\mathrm{C} 7: \mu=4.427$, sd. $=0.3736$; $\mathrm{C} 24: \mu=4.09, \mathrm{sd} .=0.3013)$ and used to estimate the best fit log normal distribution describing the time to first division. Lines and symbols that are black or red represent C7 and C24 cells, respectively. Data shown are representative of two independent experiments with similar results. Symbols denote the mean and bars represent the sd of triplicate cultures. (E) The number of C7 and $\mathrm{C} 24$ cells used to calculate their respective precursor cohorts in each division at the indicated time points was determined by flow cytometric analysis of CTV profiles and counting beads. The numbers in division 0 were excluded to better highlight time-dependent progression through division numbers. (D-E) Data shown are representative of three independent experiments with similar results. Lines and symbols that are black or red represent C7 and C24 cells, respectively. Symbols denote the mean and the error bars show the sd. of triplicate cultures. 

confounded by the egress and recirculation of activated lymphocytes. To circumvent these inherent limitations, we developed an in vitro system where CTV-labelled Tg T cells were co-cultured with $\mathrm{CD}^{+} \mathrm{T}$ cell-depleted WT splenocytes, E6 peptide, and recombinant IL-12. In addition, as IFN- $\gamma$ enhances the Th1 response in vitro $(25,26)$ but not in vivo $(27)$, we included an IFN- $\gamma$ neutralizing antibody in all the cultures to exclude the role of auto/paracrine IFN- $\gamma$ in Th1 differentiation. expansion (Fig. 2G), as well as accelerated cell division (Fig. 2H) and activation (Fig. S2B) when compared to low affinity C7 cells in vitro. At 24 h a greater fraction of high affinity $\mathrm{C} 24$ cells expressed molecules associated with early $\mathrm{T}$ cell activation, proliferation and metabolic programs, including IRF4 and phosphorylated mTOR (p-mTOR) as well as their downstream target, p-S6 (Fig. S2B). The enhanced activation was also associated with elevated c-myc levels in undivided C24 cells (Fig. S2C). As the extent of c-myc expression in undivided cells can control the number of times a cell divides before it senesces (28), these findings collectively indicate that high affinity TCRs accelerate the activation of proliferative and metabolic programs.

164 earlier than low affinity C7 cells in vitro (63h vs. 90h, Fig. 2I) (Fig. S2D). One caveat associated with this quantification method is that it does not account for how a twofold increase in the number of cells per division would affect the relative ratio of divided and undivided cells over time (8).

167 Therefore, we utilized another well-described method that accounts for the effect of cell division on the total cell number to validate our findings above (8). This method allowed us to track a cohort 169 of cells through different divisions and time-points (Fig. S2E). By calculating the time when the 
mean division number of a population of precursors is equivalent to 1 , the modelling revealed that higher affinity $\mathrm{C} 24$ cells took $95 \mathrm{~h}$ to enter their first division compared to $184 \mathrm{~h}$ for $\mathrm{C} 7$ cells (Fig. $2 J)$. Additionally, high affinity TCR signaling reduced the time it took to complete successive divisions (56 h vs. $138 \mathrm{~h}$ ) (Fig. 2I). Therefore, in addition to reducing the time to first division, our data revealed that high TCR affinity also accelerates the rate of proliferation to enhance the expansion of $\mathrm{CD}^{+} \mathrm{T}$ cell populations. Similar to our in vivo findings, high affinity $\mathrm{C} 24$ populations acquired T-bet earlier than their lower affinity counterparts in vitro (Fig. 2K). Mathematical modelling estimated that T-bet was upregulated in high affinity C24 populations 13 h earlier than lower affinity $\mathrm{C} 7$ cells (Fig. 2L). These data collectively indicate that $\mathrm{CD} 4^{+} \mathrm{T}$ cells with higher affinity TCRs undergo accelerated cell division and Th1 lineage commitment.

\section{TCR affinity determines the timing of IL-12-dependent Th1 commitment}

Multiple cytokines have been shown to contribute to the development of Th1 cells. In this regard, IL-12 is essential for Th1-dependent immunity against mycobacterial infection in both mice (29) and humans (30). Previous work has suggested that TCR signal strength also plays a role in the acquisition of the Th1 phenotype $(12,19)$. To examine the relative contribution of TCR versus cytokine signaling in Th1 differentiation, we first compared the kinetics of T-bet induction in high and low affinity $\mathrm{CD}^{+} \mathrm{T}$ cells after E6 peptide-stimulation in the presence or absence of exogenous IL-12 in vitro. We found that in the absence of IL-12 (in which TCR signaling is the major driver of differentiation), T-bet was only upregulated to an intermediate level in the majority of $\mathrm{T}$ cells (Fig. 3A). Kinetic analysis revealed that TCR stimulation alone failed to generate T-bet ${ }^{\text {high }}$ (Tbet $^{\text {hi) }} \mathrm{T}$ cell populations regardless of TCR affinity (Fig. 3B). However, the inclusion of exogenous IL-12p70 significantly increased the percentage of T-bet ${ }^{\text {hi }}$ populations in both low and high affinity 
A

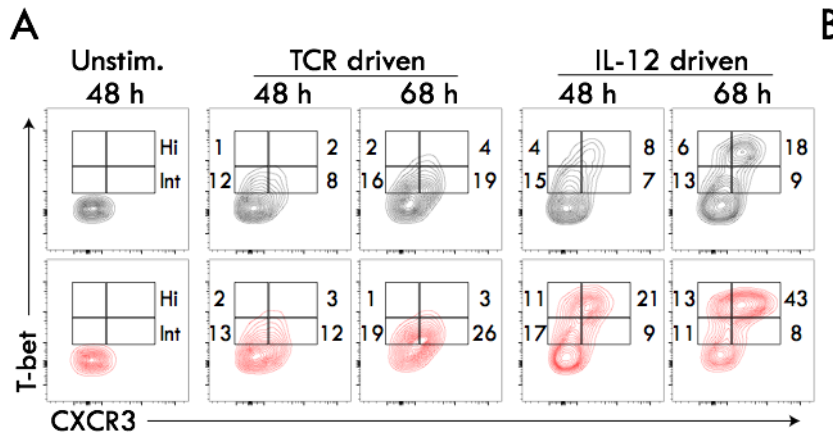

B
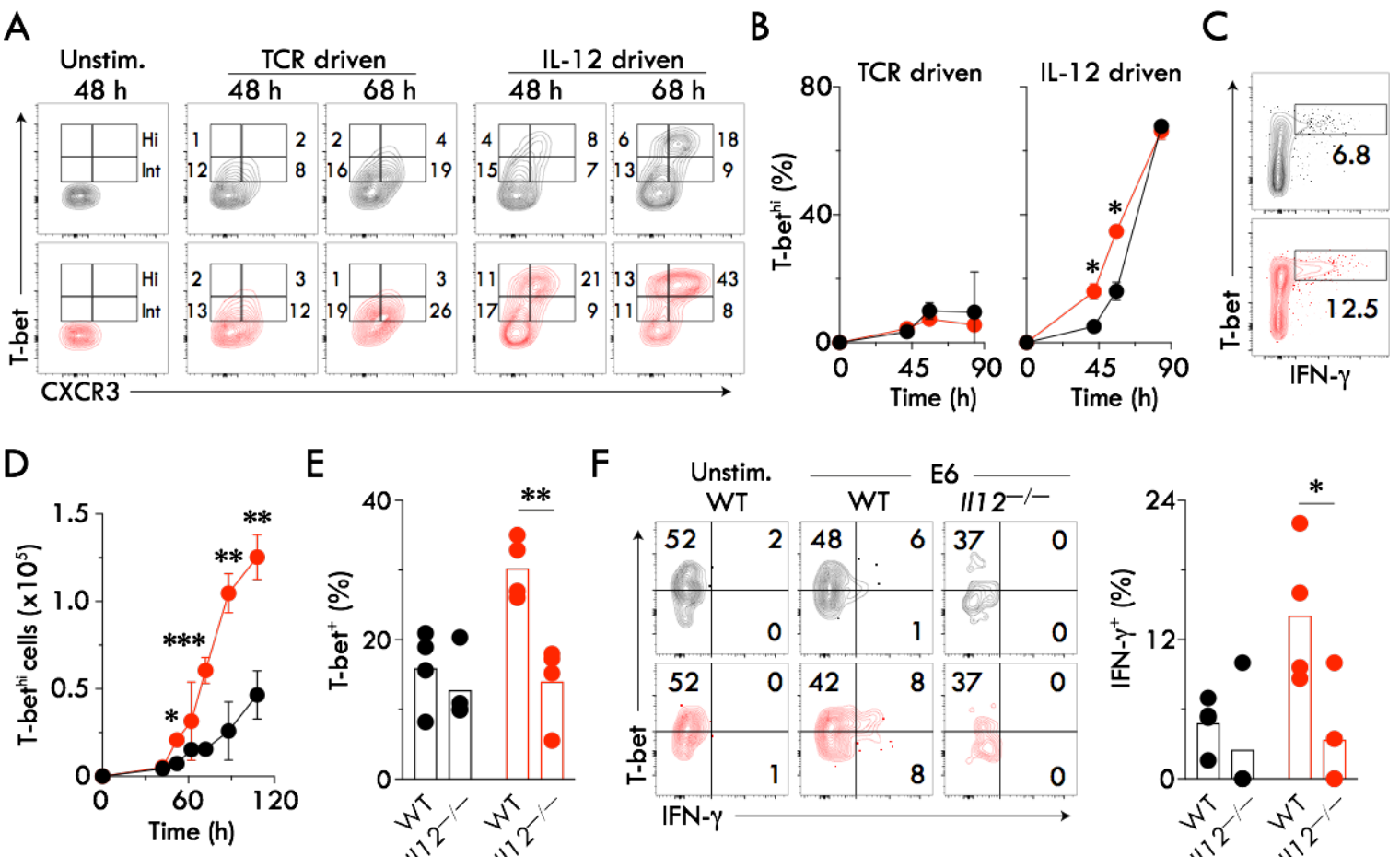

E

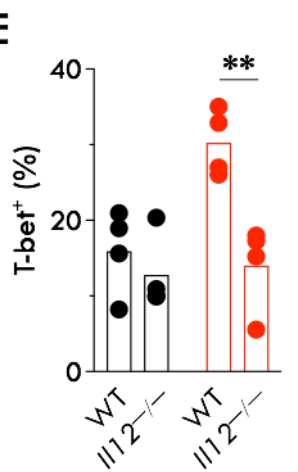

F Unstim.
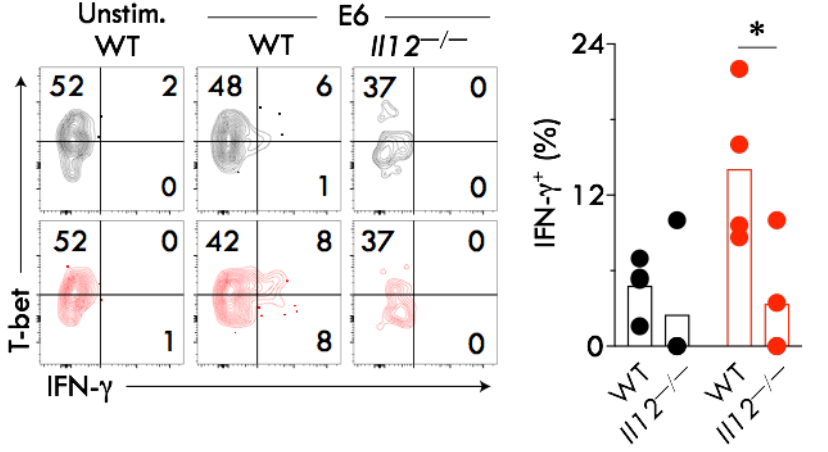

Figure. 3. High affinity TCRs accelerate the IL-12-dependent generation of Th1 effector populations.

(A-D) Purified C7 and C24 CD4 ${ }^{+} \mathrm{Tg}$ cells were cultured with CD4-depleted splenocytes from naïve B6 mice in the presence or absence of E6 peptide. In some E6-stimulated cultures, mAbs to IL-12p70, IL-4 and IFN- $\gamma$ were added (TCR-driven). In others, mAbs to IL-4 and IFN- $\gamma$, together with recombinant IL-12p70, were included (IL-12-driven). (A) Flow cytometry plots showing the levels of T-bet expression in Tg cells in the absence (TCRdriven) or presence of IL-12 (IL-12-driven). (B) Changes in the percentage of T-bet high (T-bethi) cells under different polarization conditions analysed by flow cytometry. Data shown are the mean percentage of T-bet ${ }^{\text {hi }} \mathrm{Tg}$ cells \pm sd of triplicate cultures. (C) Representative flow cytometry plot showing intracellular IFN- $\gamma$ expresseion in T-bet ${ }^{\text {hi }}$ cell populations. E6 peptide-activated C7 and C24 T cells were cultured under IL-12 driven culture conditions for $66 \mathrm{~h}$ and intracellular T-bet and IFN- $\gamma$ expression was analyzed without further re-stimulation. BFA was added to the culture $6 \mathrm{~h}$ before analysis. (D) Expansion of T-bet ${ }^{\text {hi }} \mathrm{Tg}$ cell populations in the presence of IL-12, anti-IL-4 and anti-IFN- $\gamma$. Data shown are the mean numbers of T-bet ${ }^{\text {hi }}$ Tg cells \pm sd of triplicate cultures. (E-F) Purified CD4 ${ }^{+} \mathrm{T}$ cells from C7xGFPxRag $1^{-/}$or C24xGFPxRag $1^{-/}$mice were transferred i.v. into separate naive B6 or Ill $2 p 40^{-/}$recipients 1 day prior to i.v. inoculation with BCG-E6. Data are representative of two independent experiments with similar results (4 mice / group). Symbols denote individual mice and open bars represent group means. (E) Proportion of C7 and C24 cells that express T-bet in the spleen at day 2 p.i.. (F) Representative flow cytometry plots and summary data showing the percentage of IFN- $\gamma$ expressing Tg cells in the liver 6 d.p.i.. Hepatic leukocytes were re-stimulated in the presence or absence of E6 peptide $(1 \mu \mathrm{g} / \mathrm{mL})$ for $5 \mathrm{~h}$ ex vivo before flow cytometry analysis. For all data, the lines, symbols or FACS plots in black and red represent C7 and C24 cells, respectively. Data are representative of three independent experiments with similar results. In (E) and (F), closed circles represent individual mice and bars denote the group mean. Statistical differences between $\mathrm{C} 7$ and $\mathrm{C} 24$ cells were determined by Student t-test analysis, $\left({ }^{*} \mathrm{p}<0.05, * * \mathrm{p}<0.01, * * * \mathrm{p}<0.001\right)$. 


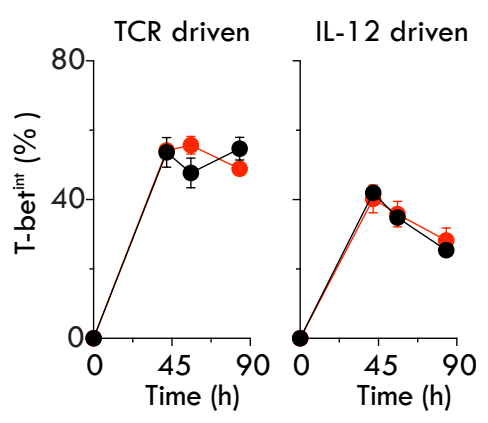

\section{Figure. S3. Kinetic analysis of intermediate $\mathbf{T}$-bet-expressing $\mathbf{T}$ cell populations.}

Purified C7 and $\mathrm{C} 24 \mathrm{CD}^{+} \mathrm{T}$ cells were cultured with CD4-depleted splenocytes in the presence or absence of E6 peptide $(0.05 \mu \mathrm{g} / \mathrm{mL})$, and exposed to TCR-driven (anti-IL-12p70, anti-IL-4 and anti-IFN- $\gamma$ mAbs) or IL-12driven $(5 \mathrm{ng} / \mathrm{mL}$ IL-12p70 and anti-IFN- $\gamma$ and anti-IL-4 mAbs) culture conditions. C7 and C24 populations expressing intermediate levels of T-bet (T-bet $\left.{ }^{\text {int }}\right)$ was determined by flow cytometry at the indicated time points. Data are representative of two independent experiments with similar results. Lines and symbols that are black or red represent C7 and C24 cells, respectively. Symbols denote the mean and the error bars show the sd. of triplicate cultures. 
T cell cultures, with the increase accelerated in the latter cultures (Fig. 3A \& B). As expected, CXCR3 induction was closely correlated with T-bet expression. When intracellular cytokine expression was evaluated without further re-stimulation, we observed that IFN- $\gamma$ was predominantly expressed by the cells expressing the highest levels of T-bet, suggesting that T-bet ${ }^{\text {hi }}$ cells represent terminally differentiated Th1 effector populations. Importantly, there was an increased accumulation of IFN- $\gamma$ expressing cells in $\mathrm{C} 24$ compared to $\mathrm{C} 7$ cultures, suggesting that high TCR affinity accelerates the generation of IL-12-dependent Th1 effectors (Fig. 3C). Kinetic analysis revealed that the IL-12 dependent generation of T-bet ${ }^{\mathrm{hi}}$ cells occurred at the expense of T-bet ${ }^{\text {int }}$ populations (Fig. S3), irrespective of TCR affinity, such that high affinity TCR signals resulted in the generation of $3-4$-fold more T-bet ${ }^{\text {hi }}$ effectors than their low affinity counterparts (Fig. 3D). Although IL-2 has been shown to enhance Th1 differentiation (31), the inclusion of IL2 neutralizing antibodies or the addition of exogenous IL-2 did not affect T-bet expression in our system (Fig. S4). These findings suggest that although TCR signals alone can induce T-bet expression, strong TCR signals cannot replace the requirement of IL-12 in the generation of fully differentiated T-bet ${ }^{\text {hi }}$ Th1 effectors.

To examine whether IL-12 plays a role in determining the Th1 phenotype of low and high affinity CD4 T cells in vivo, C7 and C24 cells were adoptively transferred into WT or Il12p40deficient $\left(I l 12^{--}\right)$recipient mice, and T-bet expression in donor T cells was assessed following BCG-E6 infection. In contrast to WT recipients, T-bet was not upregulated in the donor TCR Tg T cells in the spleens of $I l 12^{-/-}$recipient mice regardless of TCR affinity (Fig. 3E). Notably, CD4 ${ }^{+}$ T cells with high affinity TCRs failed to display expedited T-bet upregulation in the spleen at day 2 p.i. Similarly, we found that the enhanced ability of the high affinity $\mathrm{CD}^{+} \mathrm{T}$ cell populations to express IFN- $\gamma$ in response to peptide re-stimulation ex vivo was compromised if they were 


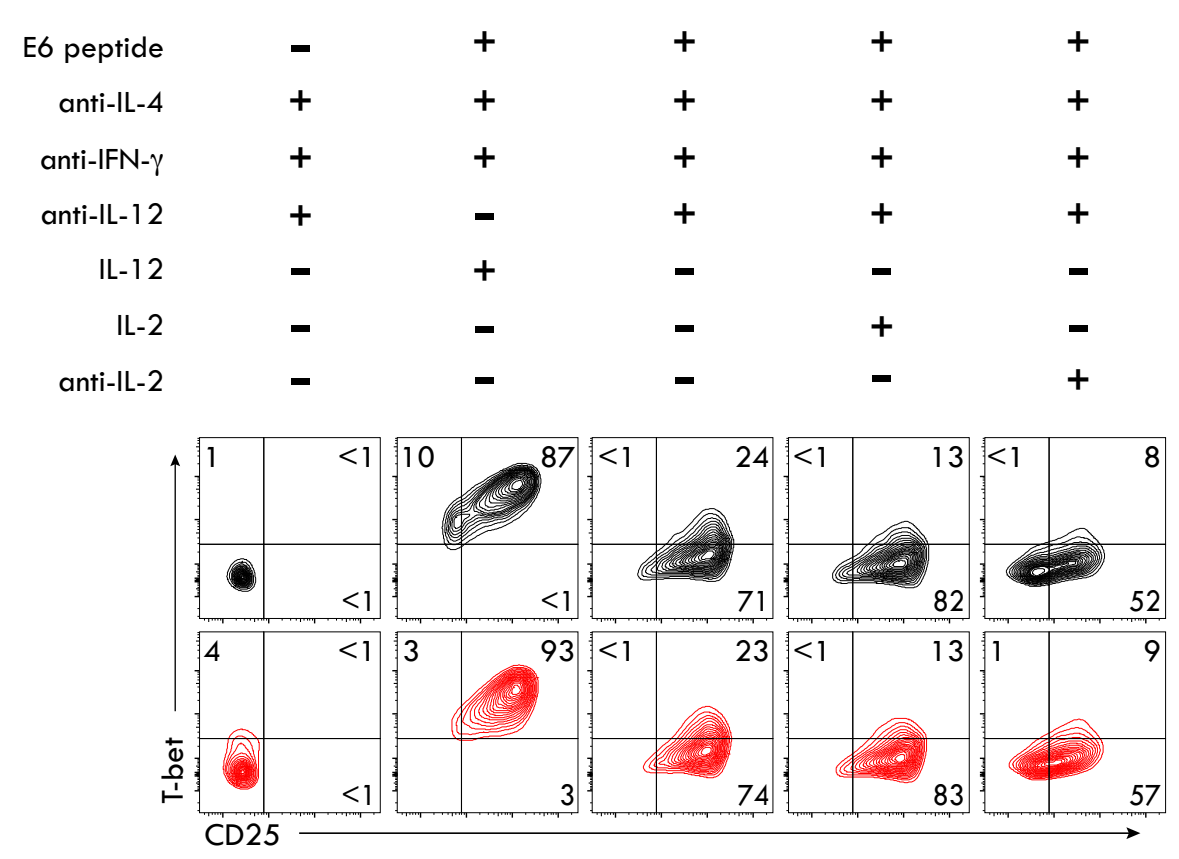

Figure. S4. IL-2 minimally affects T-bet expression in vitro.

Purified C7 and $\mathrm{C} 24 \mathrm{CD}^{+} \mathrm{T}$ cells were cultured with CD4-depleted splenocytes in the presence or absence of E6 peptide $(0.05 \mu \mathrm{g} / \mathrm{mL})$. Where indicated the T cells were incubated anti-IL-12p70, anti-IL-4, anti-IL-2 and anti-IFN- $\gamma$ mAbs, IL-12 and IL-2. T-bet and CD25 expression was analysed at $72 \mathrm{~h}$ following stimulation. Flow cytometry plots that are black and red represent C7 and C24 cells, respectively. Data are representative of two independent experiments with similar results. 
transferred into BCG-infected $I l 12^{-/}$recipients (Fig. 3F). These findings suggest that IL-12 but not TCR signals are critical for the generation of terminally differentiated Th1 effectors and that the lack of innate signaling cannot be compensated for by strong TCR signals.

\section{TCR affinity does not regulate the activation status or effector function of individual, divided}

\section{$\mathrm{CD4}^{+} \mathrm{T}$ cells}

Although TCR affinity temporally regulates the magnitude and function of Th1 populations, it may not regulate the functional output at the level of individual $\mathrm{T}$ cells $(24,32,33)$. One approach to address this possibility is to compare the mean fluorescence intensity (MFI) of molecules of interest in a given population using flow cytometry $(34,35)$. However, as low and high affinity $\mathrm{T}$ cells are activated with different kinetics (Fig. 2), simply comparing the MFI in bulk populations might skew the analysis in favor of higher affinity populations that have undergone greater division. Hence, we decided to approach this question by comparing the MFI of molecules on Tg cells in the same division.

Activated C7 and C24 T lymphocytes showed comparable expression of CD44, CD25, IRF4 and CXCR3, as well as a similar size when evaluated in the same division in vitro (Fig. 4A). This suggests that the activation status of Th cells is not intrinsically regulated by TCR affinity. Similarly, while IL-12 dose-dependent increases in the percentage of T-bet ${ }^{+}$cells were consistently more predominant in $\mathrm{C} 24$ than $\mathrm{C} 7$ cultures (Fig. 4B), T-bet levels in the two $\mathrm{T}$ cell populations in each cell division were comparable. In agreement with the findings shown above (Fig. 4A and B), enhanced T-bet expression was associated with cell cycle progression and the amount of exogenous IL-12 (Fig. 4C), confirming that TCR affinity controls the dynamics of the Th1 response rather than lineage commitment decisions occurring at the level of individual $\mathrm{T}$ cells. 

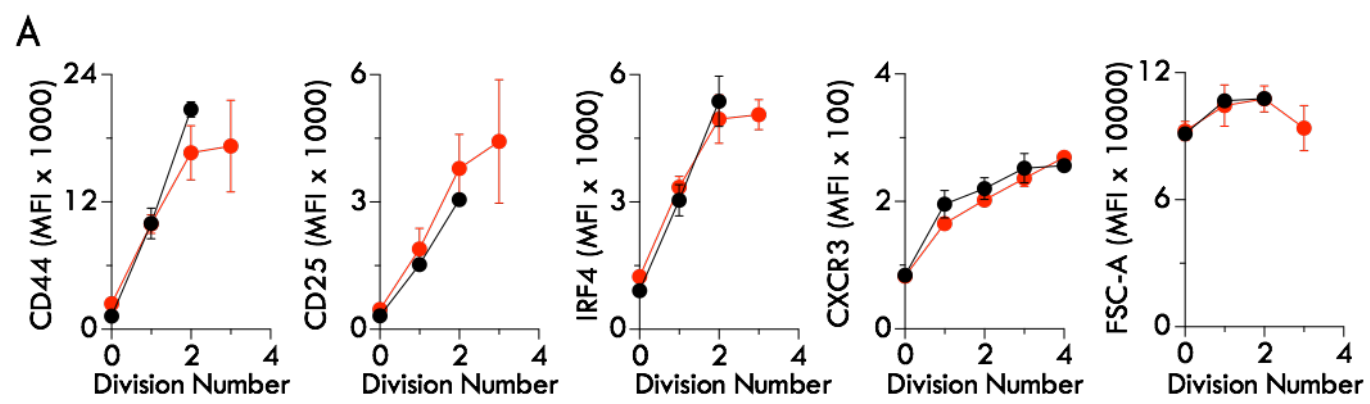

B
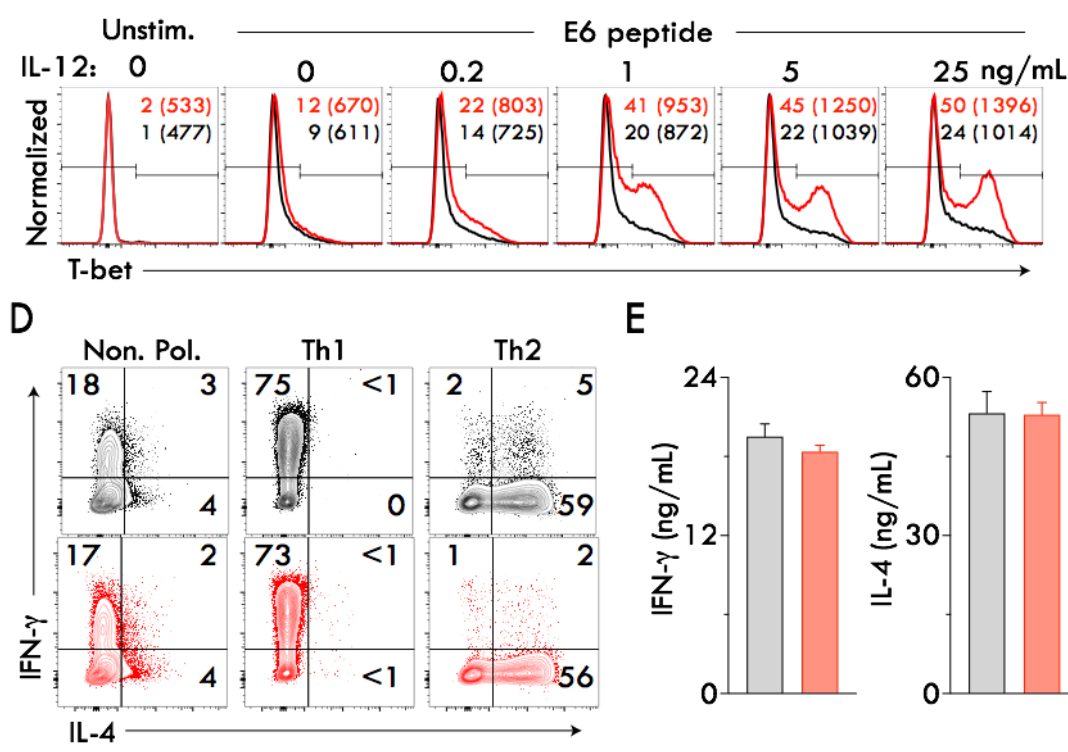

$\mathrm{E}$
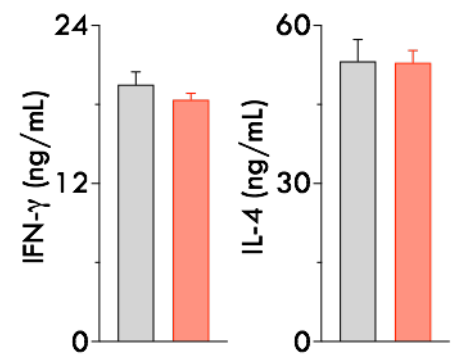

C

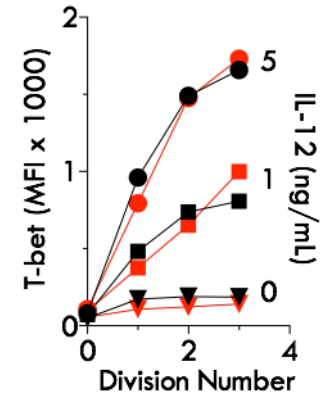

Figure. 4. TCR affinity does not determine the activation status or effector function of divided $\mathrm{CD4}^{+} \mathrm{T}$ cells.

(A-C) CTV-labelled C7 and C24 Tg cells were stimulated with E6 peptide in the presence of recombinant IL-12p70 and anti-IFN- $\gamma$ mAb for $72 \mathrm{~h}$. (A) Flow cytometric analysis of the MFI of CD44, CD25, IRF4 and CXCR3 as well as FSC-A (cell size) in each division of $\mathrm{C} 7$ and $\mathrm{C} 24$ populations at $42 \mathrm{~h}$ after peptide stimulation. (B-C) Tg cells were stimulated with E6 peptide in the presence of the graded concentrations of recombinant IL-12p70 and T-bet expression determined by flow cytometry. (B) T-bet expression in C7 and C24 Tg cell populations $60 \mathrm{~h}$ after stimulation. Numbers outside and within parentheses represent the percentage of T-bet ${ }^{+}$cells and the MFI of T-bet expression in T-bet $^{+}$populations, respectively. (C) MFI of T-bet in each division of CTV-labelled C7 and C24 cells $66 \mathrm{~h}$ after stimulation. Data shown are representative of two independent experiments with similar results. (D-E) Purified C7 and $\mathrm{C} 24 \mathrm{CD}^{+} \mathrm{T}$ cells were stimulated with E6 peptide under non-polarizing (anti-IL-12, anti-IFN- $\gamma$ and anti-IL-4 mAbs), Th1 (IL-12p70 with anti-IFN- $\gamma$ and anti-IL-4 mAbs) or Th2 (IL-4 with anti-IFN- $\gamma$ and anti-IL-12 mAbs) culture conditions for $96 \mathrm{~h}$. Following expansion in IL-2-containing medium for $48 \mathrm{~h}$, an equal number of T cells were re-stimulated with immobilized anti-CD3 in the presence (D) or absence (E) of BFA for $6 \mathrm{~h}$. (D) Intracellular IFN- $\gamma$ and IL-4 expression under the indicated culture conditions was analyzed by flow cytometry. (E) Quantification of IFN- $\gamma$ and IL-4 produced by Th1 and Th2 Tg cells by Cytokine Bead Array. Data shown are the mean \pm the sd of triplicate cultures. For all data the bars, lines, symbols or FACS plots in black and red represent C7 and C24 cells, respectively. 
Finally, low and high affinity T cells were equally susceptible to Th1 and Th2 polarization. Following priming with E6 peptide under non-polarizing, Th1 or Th2 culture conditions in vitro and re-stimulation with plate-bound anti-CD3 mAb, an equivalent proportion of $\mathrm{C} 7$ and $\mathrm{C} 24$ cells expressed the expected signature Th cytokines IFN- $\gamma$ and IL-4 (Fig. 4D). Importantly, when an equal number of cells were re-stimulated, C7 and C24 cell cultures produced comparable amounts of the signature cytokines, indicating that low and high affinity effector $\mathrm{T}$ cells have similar cytokine-producing potential at the per-cell level (Fig. 4E). These data indicate that TCR affinity itself does not intrinsically instruct the differentiation of $\mathrm{CD}^{+} \mathrm{T}$ cells or determine their activation phenotype.

250 To determine how IL-12 cooperated with TCR affinity to control the timing of Th1 polarization and ultimately the expansion of effector populations, we next examined whether TCR affinity regulated the expression of the signaling component of the IL-12R, IL-12R $\beta 2$, which is known to be absent on naïve $\mathrm{T}$ cells (36). We found that when compared to lower affinity $\mathrm{CD}^{+} \mathrm{T}$ cells, a greater fraction of high affinity $\mathrm{T}$ cells upregulated IL-12R $3248 \mathrm{~h}$ after stimulation (Fig. 5A). significantly accelerated in high affinity $\mathrm{T}$ cells leading to increased accumulation of T-bet ${ }^{\text {hi }}$ cells in $\mathrm{C} 24$ cultures (Fig. 5B). Importantly, the number of IL-12R $\beta 2$-expressing cells in high affinity 

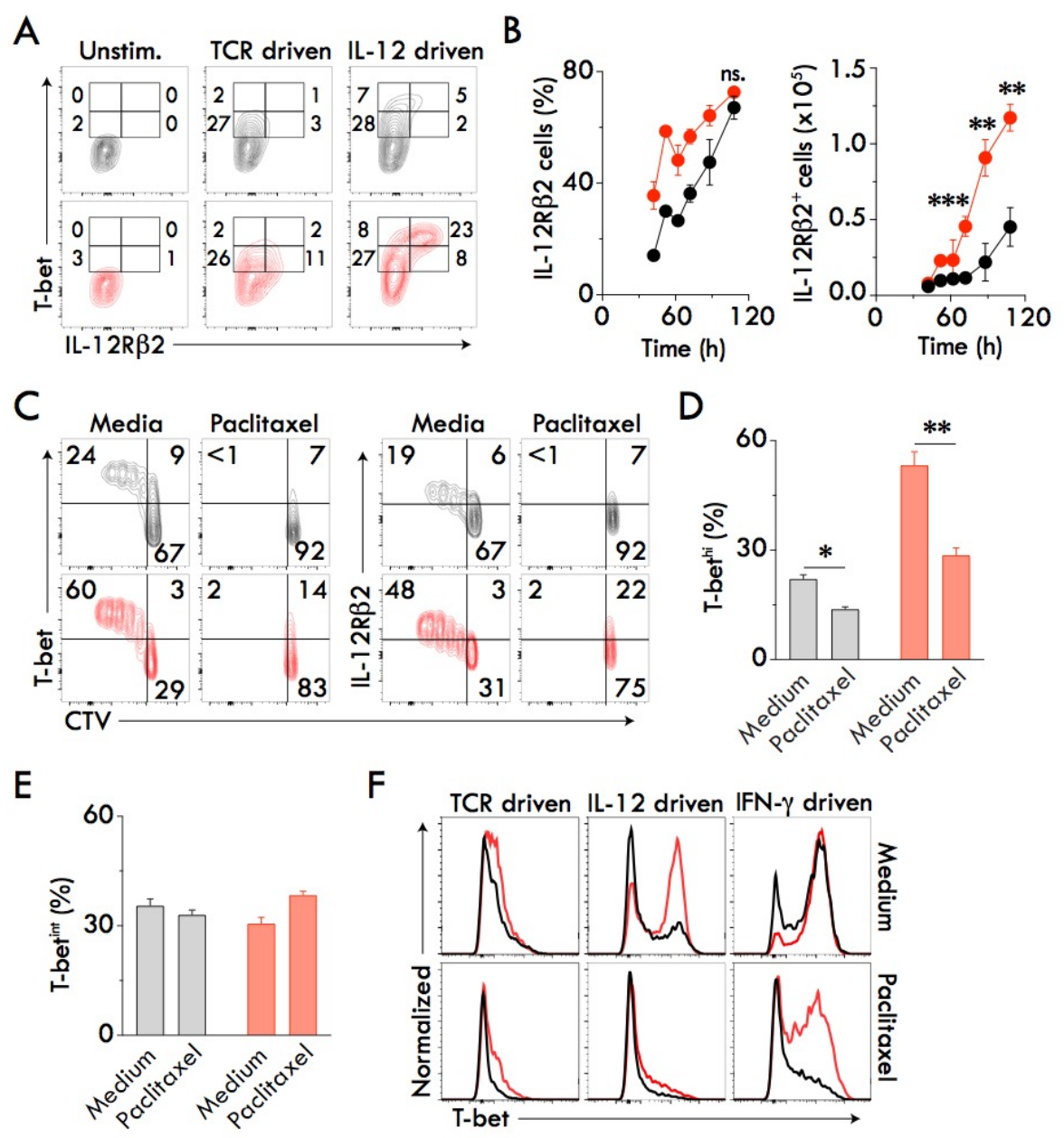

Figure. 5. TCR signal-driven IL-12R $\beta 2$ upregulation is cell division-dependent.

Purified C7 and C24 CD4 ${ }^{+} \mathrm{Tg}$ cells were cultured with CD4-depleted splenocytes from naïve B6 mice in the presence or absence of E6 peptide. (A) Flow cytometry plots showing IL-12R $\beta 2$ and T-bet expression in Tg cells $48 \mathrm{~h}$ after stimulation. In some E6-stimulated cultures, mAbs to IL-12p70, IL-4 and IFN- $\gamma$ were added (TCRdriven) while in others, mAbs to IL-4 and IFN- $\gamma$, together with recombinant IL-12p70, were included (IL-12driven). (B) Kinetic analysis of the percentage and absolute number of IL-12R $\beta 2$-expressing Tg cells by flow cytometry. Data shown are the mean \pm sd of triplicate cultures. Statistical differences between C7 and C24 cultures were determined by Students t-test $\left({ }^{*} \mathrm{p}<0.05,{ }^{* *} \mathrm{p}<0.01,{ }^{* * *} \mathrm{p}<0.001\right.$, ns., not statistically significant). The difference in the proportion of IL- $12 \mathrm{R} \beta 2^{+} \mathrm{C} 7$ and $\mathrm{C} 24$ cells was statistically significant (at least $\mathrm{p}<0.05$ ) for all time points, unless indicated otherwise. (C-E) CTV-labelled C7 and C24 T cells were stimulated with E6 peptide and IL-12 in the presence of anti-IL-4 and anti-IFN- $\gamma$ mAbs. Where indicated, paclitaxel $(200 \mathrm{nM})$ was added at the beginning of the cultures. (C) Flow cytometric analysis of T-bet and IL-12R $\beta 2$ expression on CTVlabelled C7 and C24 cells $66 \mathrm{~h}$ after peptide stimulation. The percentage of (D) Tbet ${ }^{\text {hi }}$ and (E) T-bet ${ }^{\text {int }}$ populations in $\mathrm{C} 7$ and $\mathrm{C} 24$ cultures with or without paclitaxel examined by flow cytometry at $52 \mathrm{~h}$ after peptide stimulation. Bars that are black or red represent C7 and C24 populations, respectively. Data shown are mean \pm sd of triplicate cultures. Statistical differences between untreated and paclitaxel-treated cultures were determined by Students t-test $(* \mathrm{p}<0.05, * * \mathrm{p}<0.01)$. (F) Flow cytometric analysis of the effect of paclitaxel treatment on IL-12 versus IFN- $\gamma$ augmented T-bet expression. As specified, cells were exposed to TCR-driven (anti-IL-12p70, anti-IL-4 and anti-IFN- $\gamma \mathrm{mAbs}$ ), IL-12-driven (5 ng/mL IL-12p70 and anti-IFN- $\gamma$ and anti-IL-4 mAbs) or IFN- $\gamma$-driven (anti-IL-12p70, anti-IL-4 mAbs) culture conditions and analyzed at $66 \mathrm{~h}$. All data are representative of at least two independent experiments with similar results. 
As the kinetics of T-bet and IL-12R $\beta 2$ induction mirrored that of T cell division (Fig. 2),

we hypothesized that TCR affinity timed IL-12R $\beta 2$ expression, and consequent Th1 lineage commitment, by regulating cell division. To test this, $\mathrm{Tg} \mathrm{CD}^{+} \mathrm{T}$ cells were stimulated with E6 and IL-12p70 in the presence or absence of paclitaxel, a chemical known to inhibit the G2/M phase of the cell cycle (37). As expected, paclitaxel treatment effectively blocked the proliferation of C7 and C24 cells (Fig. 5C). Supporting the key role of cell division in mediating IL-12R $\beta 2$ expression, paclitaxel treatment also impaired the upregulation of IL-12R $\beta 2$ and the subsequent expansion of T-bet-expressing cells. Importantly, paclitaxel treatment was found to selectively impair the generation of T-bet ${ }^{\text {hi }}$ cells (Fig. 5D), with T-bet ${ }^{\text {int }}$ populations being minimally affected (Fig. 5E). These data place cell division as a mechanism by which TCR affinity fine-tunes the speed of Th1 differentiation. It is worth noting that this cell division-dependent mechanism is not universally utilized in Th cell differentiation. By excluding the anti-IFN- $\gamma$ monoclonal antibody from the culture, we found that chemical inhibition of cell division prevented IL-12, but not IFN- $\gamma$-driven T-bet expression (Fig. 5F). This is likely due to the fact that in contrast to IL-12R $\beta 2$, the IFN- $\gamma$ receptor is constitutively expressed on naïve T cells $(38,39)$, and therefore, the effect of IFN- $\gamma$ on Th1 differentiation is independent of cell division.

\section{$\mathrm{CD4}^{+} \mathrm{T}$ cells with high affinity $\mathrm{TCRs}$ orchestrate accelerated anti-mycobacterial defense in}

\section{non-lymphoid tissues}

$\mathrm{CD}^{+} \mathrm{T}$ cells primed by low affinity antigens have been shown to egress from the spleen earlier than those stimulated by high affinity antigens following L. monocytogenes infection $(9,10)$. However, the role of TCR affinity in coordinating the egress of CD4 ${ }^{+} \mathrm{T}$ cell egress from secondary lymphoid organs as well as their migration into non-lymphoid tissues is unknown. We first 
assessed the anatomic localization of $\mathrm{Tg} \mathrm{CD} 4^{+} \mathrm{T}$ cells in the spleen of BCG-E6-infected mice on day 2 and 3 p.i.. At day 2 p.i., the majority of T cells, irrespective of TCR affinity, resided mainly within the $\mathrm{T}$ cell zone (Fig. 6A), with few $\mathrm{GFP}^{+} \mathrm{Tg} \mathrm{CD} 4^{+} \mathrm{T}$ cells being detected in the blood (Fig. 6B). By day 3, however, high affinity $\mathrm{C} 24$ cells began to egress from the $\mathrm{T}$ cell zone, which correlated with their increased presence in B cell follicles and in the blood of recipient mice. In contrast, the majority of lower affinity $\mathrm{C} 7$ cells remained in the $\mathrm{T}$ cell zone.

T cells traffic from lymphoid tissues into peripherally infected non-lymphoid tissues where they perform their effector function. The chemokine receptor CXCR3 has been shown to be critical for T cell entry into inflamed peripheral tissues (40), and its optimal expression is dependent on T-bet $(41,42)$. Our data confirmed a strong correlation between the expression of T-bet and CXCR3 (Fig. 2E and 3A). Following the adoptive transfer of CTV-labelled TCR Tg CD4 ${ }^{+} \mathrm{T}$ cells and i.v. infection with $\mathrm{BCG}$, a greater proportion of $\mathrm{CD}^{+} \mathrm{T}$ cells with high affinity TCRs expressed CXCR3 in the spleen when compared to those with lower affinity TCRs at day 2 p.i (Fig. 6C). By day 3 p.i, the proportion of $\mathrm{CXCR}^{+}{ }^{+} \mathrm{T}$ cells became comparable in $\mathrm{C} 7$ and $\mathrm{C} 24$ populations, which could be due to the egress of high affinity $\mathrm{CXCR}^{+} \mathrm{C} 24$ cells. Enhanced CXCR3 expression was positively correlated with $\mathrm{T}$ cell proliferation, which indicates that cells that have undergone multiple rounds of division are better equipped for peripheral tissue entry. To formally establish whether CXCR3 upregulation is dependent on T cell division, we assessed the expression of CXCR3 on peptide-activated, CTV-labelled TCR Tg T cells in the presence or absence of the cell division inhibitor paclitaxel in vitro. We confirmed that similar to T-bet, optimal CXCR3 upregulation appeared to be dependent on cell division (Fig. 6D). This suggests that cell division equips $\mathrm{CD}^{+} \mathrm{T}$ cells with the chemokine receptor that increases their entry into infected non-lymphoid tissues, with the process temporally regulated by TCR affinity. The accelerated 
A
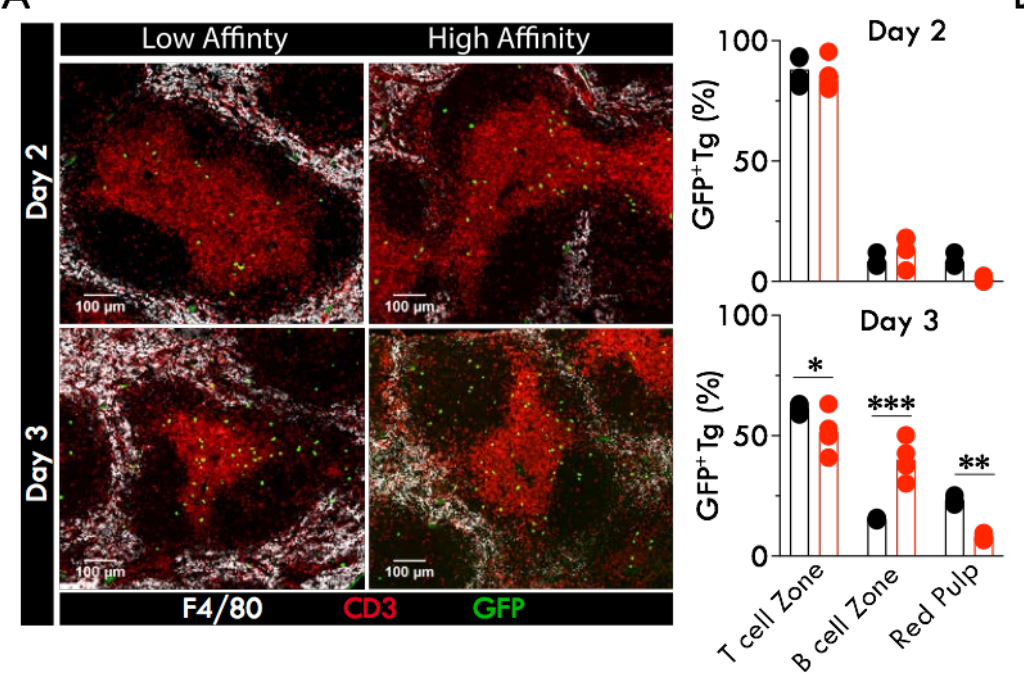

C
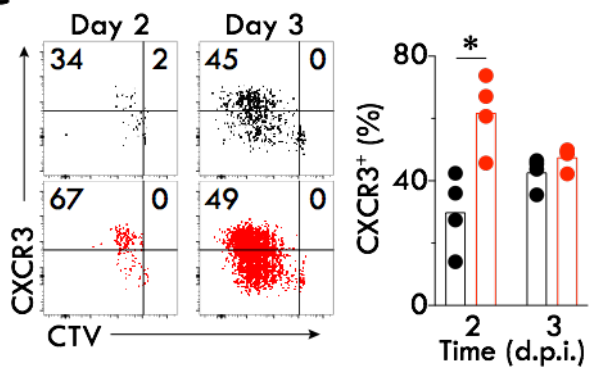

D

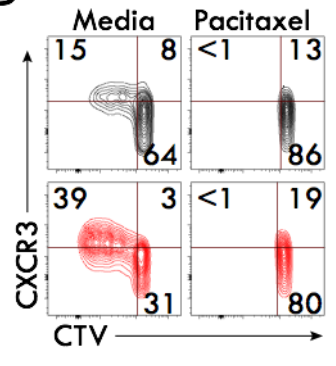

B
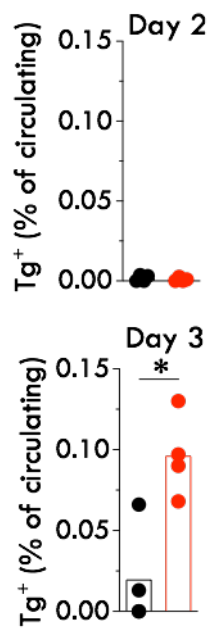

$\mathrm{E}$

$\mathrm{F}$
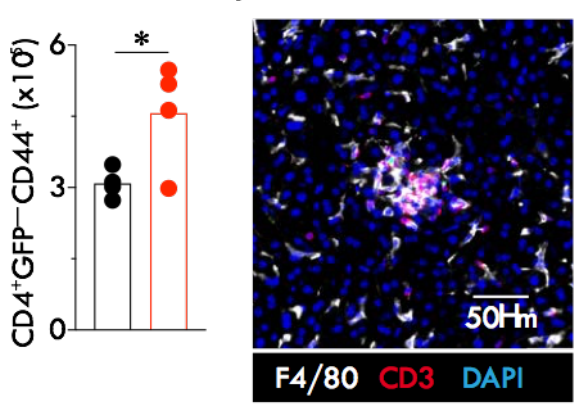

.

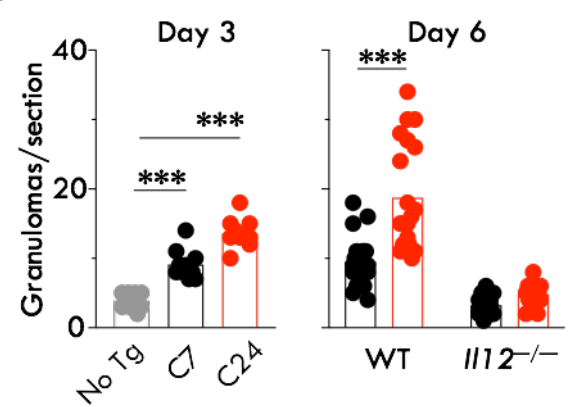

Figure. 6. High affinity TCRs accelerate Th1 cell egress from the spleen to expedite the antimycobacterial Th1 tissue response at the primary site of infection.

CTV-labelled $\mathrm{C} 7$ and $\mathrm{C} 24 \mathrm{CD}^{+}$cells were transferred into naive $\mathrm{B} 6$ recipients 1 day prior to BCG-E6 inoculation. Spleen, blood and liver samples were collected at the indicated time points. (A) Microscopic analysis and quantification of the intra-splenic localisation of $\mathrm{GFP}^{+} \mathrm{Tg}$ cells (green) in the red pulp ( $\mathrm{F} 4 / 80^{+}$, white), $\mathrm{T}$ cell zone $\left(\mathrm{CD}^{+}\right.$, red) and B cell zone ( $\mathrm{F} 4 / 80^{-}$and $\left.\mathrm{CD}^{-}\right)$at 2 and 3 d.p.i. Histograms depict the number of $\mathrm{CD}^{+} \mathrm{GFP}^{+}$cells counted in anatomic site of the spleen. Each symbol represents the percentage of Tg cells per $\mathrm{T}$ cell zone, B cell zone or the red pulp of the total number of Tg cells counted in an entire section. Each closed circle denotes one section with bars representing group means. (B) Flow cytometric analysis of the frequency of $\mathrm{C} 7$ and $\mathrm{C} 24$ cells among total $\mathrm{CD}^{+} \mathrm{T}$ cell populations in circulation at 2 and 3 d.p.i.. Closed circles denote individual mice and open bars represent group means. (C) Flow cytometric analysis of CXCR3 expression on C7 and C24 cells in the spleen at 2 and 3 d.p.i. Data are representative of two independent experiments with 
similar results ( $\mathrm{n}=4$ mice / group). Closed circles denote individual mice and open bars represent group means. (D) Flow cytometric analysis of CXCR 3 expression on CTV-labelled C7 and C24 T cells at $66 \mathrm{~h}$ after stimulation with E6 peptide, IL-12, and anti-IL-4 and anti-IFN- $\gamma$ mAbs, in the presence or absence of paclitaxel (200 nM). (E) The number of activated endogenous $\left(\mathrm{GFP}^{-} \mathrm{CD} 44^{+}\right) \mathrm{CD}^{+} \mathrm{T}$ cells in the livers of WT mice receiving $\mathrm{C} 7$ or $\mathrm{C} 24$ cells at 6 d.p.i.. Data are representative of two independent experiments with similar results $(\mathrm{n}=4$ mice / group). (F) Fluorescent micrograph showing granulomatous aggregations of $\mathrm{F} 4 / 80^{+}$(white) and $\mathrm{CD}^{+}$(red) cells in the liver of BCG-E6-infected mice at 3 d.p.i.. (G) The enumeration of the total number of hepatic granulomas $\left(\mathrm{CD}^{+}{ }^{\mathrm{DAPI}}{ }^{+} \mathrm{F} 480^{+}\right.$aggregates) in BCG-E6-infected WT or $I l 12 p 40^{-/-}$mice. Each closed circle denotes the number of granulomas in an individual section, with twelve sections counted per group. Bars represent group means. Bars, symbols or FACS plots in black and red represent C7 and C24 cells, respectively. Statistical differences between $\mathrm{C} 7$ and $\mathrm{C} 24$ cells were determined using the $(\mathbf{A}, \mathbf{G})$ two-way ANOVA or by $(\mathbf{B}, \mathbf{C}, \mathbf{E})$ the students t-test $\left(* \mathrm{p}<0.05,{ }^{*} \mathrm{p}<0.01, * * * \mathrm{p}<0.001\right)$. 
308 egress of high affinity C24 cells from the spleen was associated with a greater influx of activated $309 \mathrm{CD} 44^{+}$endogenous CD $4^{+} \mathrm{T}$ cells into the liver (Fig. 6E), indicating that high affinity $\mathrm{CD}^{+} \mathrm{T}^{\mathrm{T}}$ cells 310 promote the recruitment of endogenous $\mathrm{CD}^{+} \mathrm{T}$ cells.

311 Following mycobacterial infection, a major function of effector Th cells is to organize the 312 formation of granulomas, a key feature of the tissue response involved in containing the infection 313 (43). Hepatic granulomas in BCG-infected mice are characterized as aggregates of F4/80 314 macrophages and $\mathrm{CD}^{+}$lymphocytes (Fig. 6F), which gradually mature in size and number 315 following i.v. BCG inoculation (44). While the number of granulomas in the livers of non-T cell 316 transferred mice were low at day 3 p.i., this increased significantly in mice that received TCR Tg $317 \mathrm{CD}^{+} \mathrm{T}$ cells (Fig. 6G). The number of granulomas in the livers of mice receiving C24 cells were 318 significantly higher than those that received low affinity C7 cells, which is consistent with the 319 observation that the egress of high affinity $\mathrm{T}$ cells from the spleen was accelerated (Fig. 6B). 320 Finally, we demonstrated that the donor $\mathrm{T}$ cell-enhanced formation of hepatic granulomas is 321 dependent on IL-12 regardless of TCR affinity (Fig. 6G). Together, these data reveal that TCR 322 affinity coordinates $\mathrm{T}$ cell trafficking and accelerated host defense strategies within infected 323 tissues. 


\section{Discussion:}

325 Recent investigations have suggested that TCR signal strength (regulated intrinsically in T cells by TCR affinity, and extrinsically by the density of pMHC and co-stimulatory molecules on APCs) plays a key role in regulating $\mathrm{T}$ cell responses to a variety of infections. However, mechanisms underlying the $\mathrm{T}$ cell-intrinsic regulation of lymphocyte responses, particularly in $\mathrm{CD} 4+\mathrm{T}$ cells, are incompletely understood. In this regard, whether strong TCR signals could replace the requirement of environmental cues in imprinting the effector function of $\mathrm{CD}^{+} \mathrm{T}$ cells was undefined. We reveal that TCR affinity neither quantitatively regulates the functional output nor directly determines Th1 lineage commitment in individual $\mathrm{CD}^{+}$lymphocytes. Instead, by controlling cell division-dependent IL-12R expression, TCR affinity controls when T cells become sensitive to environmental cues, and tailor their effector function to the microbe encountered. We suggest that the primary function of TCR affinity in the $\mathrm{CD}^{+} \mathrm{T}$ cell response to intracellular infection is to control the speed of Th1 differentiation and the magnitude of effector cell populations. Interestingly, a similar observation has been reported with $\mathrm{CD}^{+} \mathrm{T}$ cells $(32,33,45)$. This cell division-dependent mechanism also helps explain how the diverse processes of a $\mathrm{T}$ cell response, proliferation, differentiation and trafficking, are temporally synchronized by TCR 340 signals.

The TCR affinity-regulated, time-dependent mechanism is particularly relevant to the understanding of host-pathogen interactions in diseases caused by persistent intracellular 343 pathogens, such as M. tuberculosis and Leishmania major. These pathogens are slow-growing and 344 can initiate a chronic infection with very small inoculants at the site of entry $(46,47)$. As shown 345 by intravital imaging analysis, antigen presentation during mycobacterial infection is limited (44). 346 Hence, $\mathrm{CD}^{+} \mathrm{T}$ cells with high TCR affinity will have a significant advantage over their low 
affinity counterparts in recognizing poorly expressed microbial peptides, and in receiving IL-12 signals to stabilize the effector function of Th1 cells. Although antigen-affinity has previously been linked to the intra-splenic localization of $\mathrm{CD}^{+} \mathrm{T}$ cells (12), whether TCR stimulation strength controls Th cell migration to infected peripheral tissues has not been investigated. Our analysis demonstrates that high affinity $\mathrm{CD}^{+} \mathrm{T}$ cell populations infiltrate the liver earlier and in

352 greater numbers, leading to an augmented granulomatous response critical for containing mycobacteria. Interestingly, this was associated with the increased recruitment of activated endogenous $\mathrm{CD}^{+} \mathrm{T}$ cells, suggesting that an additional function of Th cells with high affinity TCRs is to enhance the recruitment of other pathogen-specific T cells to the site of infection. CD4 ${ }^{+}$ T cells with high affinity TCRs likely play a pivotal role in early pathogen containment because of their ability to undergo accelerated priming, clonal expansion, differentiation and trafficking to the site of infection. Although slower at entering cell division, once activated, low affinity CD4 ${ }^{+}$ $\mathrm{T}$ cells are equipped with effector functions that are indistinguishable from high affinity $\mathrm{T}$ cells. Therefore, the sequential activation of $\mathrm{CD}^{+}{ }^{+} \mathrm{T}$ cells with high and low affinity TCRs will not only 361 provide robust but also sustained immunity against persistent pathogens. commitment. This notion is further supported by the observation that peptide-activated low and high affinity $\mathrm{CD}^{+} \mathrm{T}$ cells were equally capable of becoming Th2 cells when exogenous IL-4 was present. This finding seems to be unexpected because of the general belief that strong TCR signals promote Th1 differentiation, whereas weak signals favor the generation of Th2 cells $(48,49)$. It is possible that TCR pMHC binding affinity has a distinct function in Th differentiation compared to other TCR signal strength modulators, such as antigen dose or co-stimulatory molecules, as proposed previously (12). However, the discrepancy in the role of TCR affinity in instructing Th 
differentiation between the current and previous studies could be reconciled if the temporal regulation of T cell responses by TCR signal strength was taken into account. Since the majority of previous studies have reported $\mathrm{T}$ cell responses at the population level, in bulk cultures, at a single time point or tissue, the spatiotemporal difference in the response of low and high affinity $\mathrm{T}$ cells may not have been captured. The enhanced Th1 response associated with strong TCR stimulation at a single time point reported previously could be due to the accelerated increase in activated cell populations rather than enhanced lineage specification in individual cells.

In agreement with our findings, a previous study has shown that by modulating antigen dose or costimulatory molecule expression, strong TCR signals enhance the expression of IL$12 \mathrm{R} \beta 2$ (18). We identified the upregulation of IL-12R $\beta 2$ was dependent on cell division and timed by TCR signal strength, suggesting that cell division is an essential mechanism integrating intrinsic TCR signals and extrinsic environmental cues during Th1 differentiation. Consistent with a previous study (50), the upregulation of IL-12R $\beta 2$ occurs late after $\mathrm{T}$ cell activation and is persistently expressed, suggesting that the cells remain susceptible to IL-12 instruction for a sustained time period. Our findings support a model where TCR signals are a digital 'switch' that grant individual Th1 cells the ability to receive the instructive and selective cytokine signals for terminal differentiation and the stability of effector cell populations $(51,52)$. Indeed, IL-12 is required for the maintenance of immunity against a variety of pathogens (53-56). However, it is worth noting that the cell division-dependent mechanism underlying Th1 differentiation may not be generalized for other Th subsets. For example, IL-4R $\alpha$, constitutively expressed by naïve T cells, is transiently upregulated following TCR stimulation (57) but subsequently downregulated $(57,58)$. Therefore, the link between cell division and cytokine receptor expression may not be necessary for the differentiation of Th2 cells. 
The critical requirement for environmental cues in instructing Th1 differentiation also

394

395

396

397

398

399

400

401

402

403

404

405

406

407

408

409

410

411

412

413

414

415

suggests that the conclusions of studies investigating the role of TCR signal strength in vivo are likely influenced by the infection model. Th1 differentiation associated with strong TCR stimulation during infection with influenza virus, L. monocytogenes or Lymphocytic choriomeningitis virus (LCMV) $(12,13,19)$ has been attributed to IL-2/STAT5 signaling $(12,20)$, due partly to persistent CD25 expression on $\mathrm{CD}^{+} \mathrm{T}$ cells. While the role of IL-12 was not investigated in these studies, it is likely these pathogens activate distinct innate and adaptive immune responses compared to mycobacteria. IL-12 is only transiently or minimally produced following L. monocytogenes and LCMV infection (59). Moreover, IL-12 is either partially required (L.monocytogenes or influenza virus) or dispensable (LCMV) for Th1 differentiation in vivo (6063). Importantly, in contrast to mycobacterial infection, host control of the above-mentioned microbes predominantly requires $\mathrm{CD}^{+}$, rather than $\mathrm{CD}^{+} \mathrm{T}$ cells (64-67). Interestingly, $\mathrm{CD} 25$ was only transiently upregulated in our model. It is possible that the IL-2/CD25 feed-forward loop required for the maintenance of $\mathrm{CD} 25$ expression on $\mathrm{CD}^{+} \mathrm{T}$ cells is suppressed by mycobacterium-induced IL-12, as IL-12-dependent STAT4 activation and T-bet expression have been shown to suppress IL-2 production and IL-2R signaling $(68,69)$.

The findings reported emphasize the critical importance of TCR affinity in the timing and scaling of $\mathrm{CD}^{+} \mathrm{T}$ lymphocyte responses. They also clarify the relative roles of TCR and IL-12 signaling in Th1 differentiation. Recognizing cell division as the coordinator of distinct components of the $\mathrm{CD}^{+} \mathrm{T}$ cell response unifies the mechanisms that determine potent $\mathrm{Th} 1$ immunity. The presence of TCRs with distinct affinities for the same epitope within the immune repertoire ensures that immune surveillance against invading pathogens is rapid, sustained and independent of the level of antigen expression or stage of infection. CD4 ${ }^{+} \mathrm{T}$ cells with high affinity 
416 TCRs may orchestrate local immunity by recruiting and helping other immune populations, such 417 as lower affinity helper and cytotoxic T cells, as well as B lymphocytes. Targeting mechanisms 418 known to increase TCR signal strength, such as increasing co-stimulatory signals or modifying 419 peptide and MHC binding affinity, may lead to the development of more effective vaccination 420 strategies for protection against intracellular pathogens. 
Materials and Methods:

422

423

424

425

426

427

428

429

430

431

432

433

434

435

436

437

438

439

440

441

442

\section{Mice}

Clone 7 (C7) and Clone 24 (C24) TCR transgenic (Tg) mice specific for ESAT-6 ${ }_{1-20}$ IA $^{\mathrm{b}}$ complexes (kindly provided by Drs Eric Pamer and Michael Glickman) were generated on a C57BL/6 (B6) background as previously published (22). C7 and C24 mice were subsequently bred

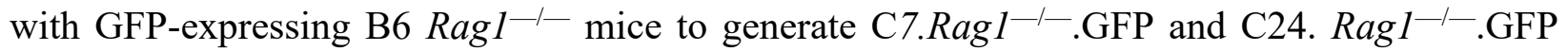
mice, respectively. The TCR transgenic animals and $I l 12 p 40^{-1-}$ mice were bred and maintained at the Centenary Institute Animal Facility. B6 recipient mice (6-8 weeks old) were purchased from Australian BioResources (Moss Vale, NSW, Australia).

\section{Mycobacterial growth and infection}

M. bovis BCG expressing a dominant epitope of the the $6 \mathrm{kDa}$ Early Secretory Antigenic Target (ESAT-6) peptide (ESAT-61-20, peptide sequence QQWNFAGIEAAASA) (termed BCG-E6) was generated using a method described previously (70). The bacterium was grown to log phase at $37^{\circ} \mathrm{C}$ in Middlebrook 7H9 broth (BD Biosciences, North Ryde, NSW, Australia) supplemented with $10 \%$ albumin-dextrose-catalase (ADC), $0.5 \%$ glycerol, $0.05 \%$ Tween 80 and $50 \mu \mathrm{g} / \mathrm{mL}$ of kanamycin and $50 \mu \mathrm{g} / \mathrm{mL}$ hygromycin (Sigma-Aldrich, North Ryde, NSW, Australia). BCG-E6 was washed in PBS and injected intravenously (i.v.) into wild-type B6 or $1 l 12 p 40^{-1}$ mice $\left(10^{6}\right.$ colony forming units (CFU) / mouse). BCG numbers in inoculates and tissue homogenates were quantified as CFU using Middlebrook 7H11 agar (BD Biosciences) supplemented with oleic acidADC (OADC) and 0.5\% glycerol. 


\section{Preparation of single cell suspensions from tissues}

444 Liver-draining lymph nodes and spleens were collected in RPMI 1640 supplemented with 2\% FCS

445 (RP2) and dissociated through $70 \mu \mathrm{m}$ strainers. For leukocyte cell isolations from the liver, 446 euthanized mice were first perfused with $10 \mathrm{~mL}$ PBS, and the livers dissociated through a $70 \mu \mathrm{m}$ 447 strainer. After washing with PBS, Liver leukocytes were enriched using 35\% Percoll (Cytiva, Marlborough, MA, USA). For blood leukocytes, up to $700 \mu \mathrm{L}$ of blood was collected via cardiac puncture into EDTA coated collection tubes (Greiner Bio-one, Kremsmünster, Austria). Peripheral blood mononuclear cells (PBMCs) were isolated by gradient centrifugation on Histopaque1083

451 (Sigma-Aldrich). Erythrocytes in single cell suspensions were lysed with ACK lysis buffer. Cells were washed in RP2 prior to viable cells being counted using trypan blue exclusion on a haemocytometer.

\section{Isolation, Labelling, Enrichment and Adoptive Transfer of TCR Tg CD4 ${ }^{+} \mathrm{T}$ cells}


465 fractions were isolated using the AutoMacsPro (Miltenyi Biotec). Enrichment of C7/C24 CD4 ${ }^{+} \mathrm{T}$ 466 cells was confirmed by flow cytometry with a purity of $\sim 95 \%$. CD4 ${ }^{+} \mathrm{T}$ cells from female mice 467 were washed in PBS, and $10^{5}$ i.v. injected into B6 or $1 l 12 p 40^{-/-}$mice $24 \mathrm{~h}$ before BCG-E6 468 infection.

\section{In vitro $T$ cell culture}

$\mathrm{CD}^{+} \mathrm{T}$ cells were cultured in RPMI 1640 medium supplemented with $10 \% \mathrm{FCS}, 100 \mathrm{U} / \mathrm{ml}$ included in the cultures. For analysis of cytokine expression without re-stimulation, 1:1000 Golgiplug (BD Biosciences) was added to the culture $5 \mathrm{~h}$ prior to flow cytometric analysis. For detection

484 of intracellular cytokine expression after re-stimulation ex vivo, up to $5 \times 10^{6}$ leukocytes were 485 incubated with $5 \mu \mathrm{g} / \mathrm{mL}$ E6 peptide or $1 \mu \mathrm{g} / \mathrm{mL} \alpha$-CD3e (clone 145-2C11, BD Biosciences) in the 
recombinant human IL-2 $(10 \mathrm{IU} / \mathrm{mL})$ prior to re-stimulation with plate-bound $\alpha-\mathrm{CD} 3$ for $6 \mathrm{~h}$ in the presence or absence of 1:1000 Golgi-plug. IFN- $\gamma$ and IL-4 protein in culture supernatants were quantified using the Cytokine Bead Array according to the manufacturer's instructions (BD Biosciences)

\section{Flow Cytometry}

All samples were acquired on the BD Fortessa using FACSDiva software (BD Biosciences) and analysis was performed using FowJo 10 (BD, Franklin Lakes, NJ, USA). Up to $5 \times 10^{6}$ cells were washed in cold FACS wash (PBS supplemented with 2\% FCS and 2mM EDTA) prior to being stained with a surface receptor antibody cocktail containing FcBlock (BD, 2.4G2) and LIVE/DEAD fixable blue dead cell stain (Thermo Fisher Scientific) for 30 minutes at $4^{\circ} \mathrm{C}$. For analysis of IL-12R $\beta 2$ expression, cells were stained separately in FACS wash containing IL12R 32 -Biotin (REA200, Miltenyi Biotec) and FcBlock for 30 minutes at $4^{\circ} \mathrm{C}$. Where appropriate, cells were stained in FACS wash containing streptavidin PE-Cy/7 conjugates for 20 minutes at $4^{\circ} \mathrm{C}$ before being incubated with the surface antibody cocktail. The following monoclonal antibodies were used for the detection of cell surface markers: CD4 (RM4-5), CD44 (IM7), CD25 (PC61) (all from BD Biosciences); and CXCR3 (CXCR3-173, BioLegend, San Diego, CA, USA). Cells were washed in FACS buffer prior to acquisition.

For detection of intracellular transcription factors and cytokines, surface stained cells were fixed with $100 \mu \mathrm{L}$ Cytofix/Cytoperm (BD Biosciences) for 15 minutes at $4^{\circ} \mathrm{C}$ to preserve GFP expression. To improve transcription factor staining, in some experiments, cells were then incubated with $100 \mu \mathrm{L}$ 1x Fixation/Permeabilization solution (Thermo Fisher Scientific) for 30 
minutes at $4^{\circ} \mathrm{C}$. Cells were thoroughly washed in $1 \mathrm{x}$ Permeabilization buffer (Thermo Fisher Scientific). Cells were incubated for 1 hour at $4^{\circ} \mathrm{C}$ in $1 \mathrm{x}$ Permeabilization buffer containing a cocktail of the following monoclonal antibodies: IFN- $\gamma$ (XMG1.2), IL-4 (11B11) (both from BD Biosciences); T-bet (4B10, Biolegend), Ki-67 (SolA15) and IRF4 (3E4) (both from Thermo Fisher Scientific). Cells were washed in 1x Permeabilization buffer and resuspended in FACS buffer prior to acquisition.

For detection of phosphorylated proteins and myc, at the indicated time points, cells were immediately fixed and permeabilized using the Transcription Factor Phospho Buffer set (BD Biosciences) as per the manufacturers instructions. For analysis of myc expression, cells were incubated in 1xPermbuffer III (BD) containing purified anti-myc (clone D84C12, Cell Signaling, Danver, MA, USA) or rabbit IgG isotype matched control for 1 hour at $4^{\circ} \mathrm{C}$. Cells were washed and then incubated with polyclonal anti-rabbit $\operatorname{IgG}(\mathrm{H}+\mathrm{L})$ (Thermo Fisher Scientific) for 1 hour at $4^{\circ} \mathrm{C}$. For the detection of phosphorylated proteins, cells were incubated with $1 x$ Permbuffer III containing monoclonal antibodies against phosphorylated-S6-Ribosomal protein (D57.2.2E, Cell Signaling) or phosphorylated-mTOR (clone MRRBY, Thermo Fisher Scientific) for 30 minutes at $4^{\circ} \mathrm{C}$. Cells were thoroughly washed in $1 \mathrm{x}$ Permbuffer III, FACS wash and then incubated in FACS wash containing monoclonal antibodies targeting cell surface markers and FcBlock for 30 minutes at $4^{\circ} \mathrm{C}$. Cells were thoroughly washed in FACS wash prior to acquisition.

\section{Organ collection and processing for imaging}

Spleens and the caudate lobe of livers were collected for microscopic imaging. The spleens were cut into quarters. Tissues were then placed in $5 \mathrm{~mL}$ of $4 \%$ PFA for 12 hours at $4^{\circ} \mathrm{C}$. Fixed tissues were then transferred into 30\% (v/v) sucrose (Sigma-Aldrich) in PBS. After 24 hours tissues were 
embedded in Optimal Cutting Temperature (OCT) compound (VWR Chemicals, Atlanta, GA, USA) and snap frozen on a metal bar cooled by dry ice. Frozen tissue blocks were then sectioned at $10 \mu \mathrm{m}$ on a Shandon Cryotome E (Thermo Fisher Scientific). Sections were stored at $-80^{\circ} \mathrm{C}$ until use.

Frozen slides were allowed to thaw at room temperature for $10 \mathrm{~min}$ before proceeding with staining. Sections were blocked in PBS containing 3\% (v/v) normal goat serum $(0.1 \%(\mathrm{v} / \mathrm{v})$ Triton $\mathrm{X}-100$ in PBS for 30 mins at RT. Sections were incubated overnight at $4^{\circ} \mathrm{C}$ with anti-CD3 (17A2), -B220 (RA3-6B2) (both from BD Biosciences), and/or -F4/80 (Thermo Fisher Scientific) antibodies diluted in 3\% (v/v) normal goat serum (Cell Signaling) in PBS. Sections were washed 3 times in PBS, and the incubated with streptavidin AF555 (Thermo Fisher Scientific) for 1 hour at RT. Sections were washed 3 times in PBS and then mounted using Prolong Gold (Thermo Fisher Scientific). Sections were imaged on a Deltavision Personal (GE Healthcare Life Sciences, Taipei, Taiwan) and image analysis was performed using FIJI software v1.51w (NIH Research Services, Bethesda, MD, USA).

\section{Determination of the intrasplenic localisation of transferred $T$ cells and enumeration of}

\section{hepatic granulomas}

The number of adoptively transferred TCR Tg CD4 $4^{+} \mathrm{T}$ cells, defined based on their dual expression of GFP and CD3, were counted using the cell counter plugin on FIJI software v1.51w. Two nonconsecutive sections with similar size from each spleen were analyzed. The number of double positive T cells was quantified in 3 different distinct regions of the spleen: $\mathrm{T}$ cell zone $\left(\mathrm{CD}^{+}\right), \mathrm{B}$ cell follicles $\left(\mathrm{CD}^{-} \mathrm{F}^{-} / 80^{-}\right)$and the red pulp $\left(\mathrm{F} 4 / 80^{+}\right)$. The number of hepatic granulomas $\left(\mathrm{CD}^{+}{ }^{\mathrm{DAPI}}{ }^{+} \mathrm{F} 480^{+}\right.$aggregates with a size greater than $\left.50 \mu \mathrm{M}\right)$ were counted in ten non- 
consecutive sections. Section selected for counting were more than $50 \mu \mathrm{M}$ apart to avoid double counting of the same hepatic granulomas.

\section{Proliferation Modeling}

Quantification of cell numbers for in vitro was performed by adding a known number of Rainbow Beads (BD) prior to sample acquisition. FlowJo 10 was used to model cell division numbers respective to an unstimulated control. The same gating of cell division numbers were used for responding samples within the time-point. This was used to determine the proportion of cells in each division and at each time-point. $1 \times 10^{4}$ Rainbow Beads were included prior to flow cytometric acquisition to enumerate the number of cells in each division. Since only a proportion of a starting population of cells will have participated in cell division by the end of an experiment, the precursor cohort method allows us to trace cells that have actually divided (precursor cohort) to quantify the time required to reach first division and the rate of subsequent cell cycles. The methods are described by (8) and described here in brief. Precursor cohort numbers $\left(\mathrm{C}_{\mathrm{i}}\right)$ are quantified in accordance to the equation below.

$$
C_{i}=\frac{\text { total number of cells in division } i}{2^{\text {division } i}}
$$

The number of precursor cells in each division at each time point can be plotted. The average division number of cells is estimated by using the equation below. Here, $\mathrm{K}$ is the maximum number of divisions that can be resolved.

$$
\text { mean division number }=\frac{\sum_{k=0}^{K} k \cdot C_{k}}{\sum_{k=0}^{K} C_{k}}
$$

The mean division number is plotted against time. When a trend line is fitted to the data using linear regression analysis, the equation of the line $(y=m x)$ can be used to calculate the time to 
577 first division and the rate of subsequent divisions. Here, $y$ is the division number, $m$ the gradient, 578 and $x$ is time. Using this equation, we can work out the time (x) to first division by substituting $\mathrm{y}$

579 for division number 1 . Subsequent division times are calculated by taking the inverse of the 580 gradient:

$$
\text { Division time }=\frac{1}{m}
$$

\section{Estimating the mean distribution of times to first division and T-bet expression}

584 The proportion of undivided or T-bet-negative cells across different time points is fitted with an inverted cumulative lognormal distribution. The best-fit values of the mean $(\mu)$ and standard deviation (sd.) for this distribution were used to determine the probability lognormal distribution of times to first division $(8,23,24)$ or T-bet expression. The $\mu$ of the probability distribution provides an estimate for the time to first division or T-bet expression.

594 Tukey's multiple comparisons test. Results with $\mathrm{p}<0.05$ were deemed statistically significant, where; $* \mathrm{p}<0.05, * * \mathrm{p}<0.01, * * * \mathrm{p}<0.001$ 


\section{Acknowledgments:}

598 We thank E. Pamer and M. Glickman (Memorial Sloan-Kettering Cancer Center) for providing 599 the transgenic T cell mouse lines. We also thank P. Hodgkin and S. Heinzel (Walter and Eliza Hall 600 Institute) and D. Jankovic (NIH) for reading this manuscript. We acknowledge M. Coleman, S.

601 Warner and H. Rathbone for their thoughtful discussion, and M. Soud for proofreading this 602 manuscript. Finally, we are grateful to the Centenary Institute Animal and Flow Cytometry Core 603 facilities for their support.

604

605 Funding:

606 This work was supported by a National Health and Medical Research Council (NHMRC) of 607 Australia Project (APP1146677). N.D.B., L.D.., and T.A.C were supported by Australian 608 Postgraduate Awards.

609

610 Competing interests:

611 The authors declare no competing interests. 


\section{References:}

1. A. V. Gett, P. D. Hodgkin, Cell division regulates the T cell cytokine repertoire, revealing a mechanism underlying immune class regulation. Proc Natl Acad Sci U S A 95, 94889493 (1998).

2. J. J. Bird et al., Helper T cell differentiation is controlled by the cell cycle. Immunity 9 , 229-237 (1998).

3. A. Richter, M. Lohning, A. Radbruch, Instruction for cytokine expression in T helper lymphocytes in relation to proliferation and cell cycle progression. $J$ Exp Med 190, 14391450 (1999).

4. H. H. Chu et al., Positive selection optimizes the number and function of MHCII-restricted CD4+ T cell clones in the naive polyclonal repertoire. Proc Natl Acad Sci U S A 106, 11241-11245 (2009).

5. J. J. Moon et al., Naive CD4(+) T cell frequency varies for different epitopes and predicts repertoire diversity and response magnitude. Immunity 27, 203-213 (2007).

6. N. J. Tubo, M. K. Jenkins, TCR signal quantity and quality in CD4(+) T cell differentiation. Trends Immunol 35, 591-596 (2014).

7. M. Ruterbusch, K. B. Pruner, L. Shehata, M. Pepper, In Vivo CD4(+) T Cell Differentiation and Function: Revisiting the Th1/Th2 Paradigm. Annu Rev Immunol 38, 705-725 (2020).

8. J. M. Marchingo et al., T cell signaling. Antigen affinity, costimulation, and cytokine inputs sum linearly to amplify T cell expansion. Science 346, 1123-1127 (2014).

9. D. Zehn, S. Y. Lee, M. J. Bevan, Complete but curtailed T-cell response to very lowaffinity antigen. Nature 458, 211-214 (2009). 
10. A. J. Ozga et al., pMHC affinity controls duration of CD8+ T cell-DC interactions and imprints timing of effector differentiation versus expansion. $J$ Exp Med 213, 2811-2829 (2016).

11. N. Fazilleau, L. J. McHeyzer-Williams, H. Rosen, M. G. McHeyzer-Williams, The function of follicular helper $\mathrm{T}$ cells is regulated by the strength of $\mathrm{T}$ cell antigen receptor binding. Nat Immunol 10, 375-384 (2009).

12. S. Keck et al., Antigen affinity and antigen dose exert distinct influences on CD4 T-cell differentiation. Proc Natl Acad Sci U S A 111, 14852-14857 (2014).

13. D. I. Kotov et al., TCR Affinity Biases Th Cell Differentiation by Regulating CD25, Eef1e1, and Gbp2. J Immunol (2019).

14. J. Zhu, T Helper Cell Differentiation, Heterogeneity, and Plasticity. Cold Spring Harb Perspect Biol 10 (2018).

15. J. Magram et al., IL-12-deficient mice are defective in IFN gamma production and type 1 cytokine responses. Immunity 4, 471-481 (1996).

16. C.-S. Hsieh et al., Development of TH1 CD4+ T cells through IL-12 produced by Listeriainduced macrophages. Science 260, 547-549 (1993).

17. G. Trinchieri, Interleukin-12 and the regulation of innate resistance and adaptive immunity. Nat Rev Immunol 3, 133-146 (2003).

18. N. van Panhuys, F. Klauschen, R. N. Germain, T-cell-receptor-dependent signal intensity dominantly controls CD4(+) T cell polarization In Vivo. Immunity 41, 63-74 (2014).

19. J. P. Snook, C. Kim, M. A. Williams, TCR signal strength controls the differentiation of CD4(+) effector and memory T cells. Sci Immunol 3 (2018). 
657 20. D. DiToro et al., Differential IL-2 expression defines developmental fates of follicular $658 \quad$ versus nonfollicular helper T cells. Science 361 (2018).

659 21. N. J. Tubo et al., Single naive CD4+ T cells from a diverse repertoire produce different $660 \quad$ effector cell types during infection. Cell 153, 785-796 (2013).

661 22. A. M. Gallegos et al., Control of $\mathrm{T}$ cell antigen reactivity via programmed TCR 662 downregulation. Nat Immunol 17, 379-386 (2016).

663 23. V. R. Buchholz et al., Disparate individual fates compose robust CD8+ T cell immunity. Science 340, 630-635 (2013).

24. C. Gerlach et al., Heterogeneous differentiation patterns of individual CD8+ T cells. Science 340, 635-639 (2013).

25. M. Afkarian et al., T-bet is a STAT1-induced regulator of IL-12R expression in naive CD4+ T cells. Nat Immunol 3, 549-557 (2002).

26. A. A. Lighvani et al., T-bet is rapidly induced by interferon- $\gamma$ in lymphoid and myeloid cells. Proceedings of the National Academy of Sciences 98, 15137-15142 (2001).

27. B. Nandi, S. M. Behar, Regulation of neutrophils by interferon-gamma limits lung inflammation during tuberculosis infection. J Exp Med 208, 2251-2262 (2011).

28. S. Heinzel et al., A Myc-dependent division timer complements a cell-death timer to regulate T cell and B cell responses. Nat Immunol 18, 96-103 (2017). tuberculosis. The Journal of experimental medicine 186, 39-45 (1997). model. Annu Rev Immunol 20, 581-620 (2002). 
680 31. W. Liao, J. X. Lin, L. Wang, P. Li, W. J. Leonard, Modulation of cytokine receptors by IL-

681

682

683

684

685

686

687

688

689

690

691

692

693

694

695

696

697

698

699

700

701

702

2 broadly regulates differentiation into helper T cell lineages. Nat Immunol 12, 551-559 (2011).

32. A. C. Richard et al., T cell cytolytic capacity is independent of initial stimulation strength. Nat Immunol 19, 849-858 (2018).

33. M. Prlic, G. Hernandez-Hoyos, M. J. Bevan, Duration of the initial TCR stimulus controls the magnitude but not functionality of the CD8+ T cell response. $J \operatorname{Exp}$ Med 203, 21352143 (2006).

34. K. A. Allison et al., Affinity and dose of TCR engagement yield proportional enhancer and gene activity in CD4+ T cells. Elife 5 (2016).

35. V. Krishnamoorthy et al., The IRF4 Gene Regulatory Module Functions as a Read-Write Integrator to Dynamically Coordinate T Helper Cell Fate. Immunity 47, 481-497 e487 (2017).

36. S. J. Szabo, A. S. Dighe, U. Gubler, K. M. Murphy, Regulation of the interleukin (IL)-12R beta 2 subunit expression in developing T helper 1 (Th1) and Th2 cells. J Exp Med 185, 817-824 (1997).

37. P. B. Schiff, S. B. Horwitz, Taxol stabilizes microtubules in mouse fibroblast cells. Proc Natl Acad Sci U S A 77, 1561-1565 (1980).

38. E. A. Bach et al., Ligand-induced autoregulation of IFN-gamma receptor beta chain expression in T helper cell subsets. Science 270, 1215-1218 (1995).

39. A. Pernis et al., Lack of interferon gamma receptor beta chain and the prevention of interferon gamma signaling in TH1 cells. Science 269, 245-247 (1995).

40. J. R. Groom, A. D. Luster, CXCR3 in T cell function. Exp Cell Res 317, 620-631 (2011). 
703

704

705

706

707

708

709

710

711

712

713

714

715

716

717

718

719

720

721

722

723

724

725

41. G. M. Lord et al., T-bet is required for optimal proinflammatory CD4+ T-cell trafficking. Blood 106, 3432-3439 (2005).

42. V. R. Taqueti et al., T-bet controls pathogenicity of CTLs in the heart by separable effects on migration and effector activity. J Immunol 177, 5890-5901 (2006).

43. A. O'Garra et al., The immune response in tuberculosis. Annu Rev Immunol 31, 475-527 (2013).

44. J. G. Egen et al., Intravital imaging reveals limited antigen presentation and $\mathrm{T}$ cell effector function in mycobacterial granulomas. Immunity 34, 807-819 (2011).

45. C. Y. Ma, J. C. Marioni, G. M. Griffiths, A. C. Richard, Stimulation strength controls the rate of initiation but not the molecular organisation of TCR-induced signalling. Elife 9 (2020).

46. N. Kimblin et al., Quantification of the infectious dose of Leishmania major transmitted to the skin by single sand flies. Proc Natl Acad Sci U S A 105, 10125-10130 (2008).

47. D. Saini et al., Ultra-low dose of Mycobacterium tuberculosis aerosol creates partial infection in mice. Tuberculosis (Edinb) 92, 160-165 (2012).

48. S. Constant, C. Pfeiffer, A. Woodard, T. Pasqualini, K. Bottomly, Extent of T cell receptor ligation can determine the functional differentiation of naive CD4+ T cells. $J$ Exp Med $\mathbf{1 8 2}$, 1591-1596 (1995).

49. C. Pfeiffer et al., Altered peptide ligands can control CD4 T lymphocyte differentiation in vivo. J Exp Med 181, 1569-1574 (1995).

50. E. G. Schulz, L. Mariani, A. Radbruch, T. Höfer, Sequential polarization and imprinting of type $1 \mathrm{~T}$ helper lymphocytes by interferon- $\gamma$ and interleukin-12. Immunity 30, 673-683 (2009). 
51. A. C. Mullen et al., Role of T-bet in Commitment of TH1 Cells Before IL-12-Dependent Selection. Science 292, 1907-1910 (2001).

52. R. J. Boyton, D. M. Altmann, Is selection for TCR affinity a factor in cytokine polarization? Trends Immunol 23, 526-529 (2002).

53. G. Yap, M. Pesin, A. Sher, Cutting edge: IL-12 is required for the maintenance of IFNgamma production in $\mathrm{T}$ cells mediating chronic resistance to the intracellular pathogen, Toxoplasma gondii. J Immunol 165, 628-631 (2000).

54. C. G. Feng et al., Maintenance of pulmonary Th1 effector function in chronic tuberculosis requires persistent IL-12 production. The Journal of Immunology 174, 4185-4192 (2005).

55. A. Y. Park, B. D. Hondowicz, P. Scott, IL-12 is required to maintain a Th1 response during Leishmania major infection. J Immunol 165, 896-902 (2000).

56. L. Stobie et al., The role of antigen and IL-12 in sustaining Th1 memory cells in vivo: IL12 is required to maintain memory/effector Th1 cells sufficient to mediate protection to an infectious parasite challenge. Proc Natl Acad Sci U S A 97, 8427-8432 (2000).

57. Y. Tanaka et al., $\mathrm{T}$ helper type 2 differentiation and intracellular trafficking of the interleukin 4 receptor-alpha subunit controlled by the Rac activator Dock2. Nat Immunol 8, 1067-1075 (2007).

58. G. Perona-Wright, K. Mohrs, K. D. Mayer, M. Mohrs, Differential regulation of IL4Ralpha expression by antigen versus cytokine stimulation characterizes Th2 progression in vivo. J Immunol 184, 615-623 (2010).

59. S. J. Keppler, K. Rosenits, T. Koegl, S. Vucikuja, P. Aichele, Signal 3 cytokines as modulators of primary immune responses during infections: the interplay of type I IFN and IL-12 in CD8 T cell responses. PLoS One 7, e40865 (2012). 
60. N. N. Orgun, M. A. Mathis, C. B. Wilson, S. S. Way, Deviation from a strong Th1dominated to a modest Th17-dominated CD4 T cell response in the absence of IL-12p40

61. S. S. Way, C. Havenar-Daughton, G. A. Kolumam, N. N. Orgun, K. Murali-Krishna, IL12 and type-I IFN synergize for IFN-gamma production by CD4 T cells, whereas neither are required for IFN-gamma production by CD8 T cells after Listeria monocytogenes infection. J Immunol 178, 4498-4505 (2007).

62. A. Bot, E. Rodrigo, T. Wolfe, S. Bot, M. G. Von Herrath, Infection-triggered regulatory mechanisms override the role of STAT 4 in control of the immune response to influenza virus antigens. $J$ Virol 77, 5794-5800 (2003).

63. A. Oxenius, U. Karrer, R. M. Zinkernagel, H. Hengartner, IL-12 is not required for induction of type 1 cytokine responses in viral infections. J Immunol 162, 965-973 (1999).

64. K. Mozdzanowska, K. Maiese, W. Gerhard, Th cell-deficient mice control influenza virus infection more effectively than Th- and B cell-deficient mice: evidence for a Thindependent contribution by B cells to virus clearance. J Immunol 164, 2635-2643 (2000).

65. S. H. Kaufmann, C. H. Ladel, Role of $\mathrm{T}$ cell subsets in immunity against intracellular bacteria: experimental infections of knock-out mice with Listeria monocytogenes and Mycobacterium bovis BCG. Immunobiology 191, 509-519 (1994).

66. M. E. Mielke, G. Niedobitek, H. Stein, H. Hahn, Acquired resistance to Listeria monocytogenes is mediated by Lyt-2+ T cells independently of the influx of monocytes into granulomatous lesions. J Exp Med 170, 589-594 (1989). 
770 67. R. Ahmed, L. D. Butler, L. Bhatti, T4+ T helper cell function in vivo: differential requirement for induction of antiviral cytotoxic T-cell and antibody responses. J Virol 62, 2102-2106 (1988).

773

774

775

776

777

778

779

780

68. E. S. Hwang, J. H. Hong, L. H. Glimcher, IL-2 production in developing Th1 cells is regulated by heterodimerization of RelA and T-bet and requires T-bet serine residue 508 . J Exp Med 202, 1289-1300 (2005).

69. A. V. Villarino et al., Helper T cell IL-2 production is limited by negative feedback and STAT-dependent cytokine signals. J Exp Med 204, 65-71 (2007).

70. K. A. Prendergast et al., The Ag85B protein of the BCG vaccine facilitates macrophage uptake but is dispensable for protection against aerosol Mycobacterium tuberculosis infection. Vaccine 34, 2608-2615 (2016). 